\title{
Bivalves Antárticos e Subantárticos coletados durante as Expedições Científicas Brasileiras à Antártica I a IX (1982-1991)
}

\author{
Walter Narchi ${ }^{1}$ \\ Osmar Domaneschi ${ }^{1}$ \\ Flávio Dias Passos ${ }^{1}$
}

\begin{abstract}
Antarctic and Subantarctic bivalves collected during the Scientific Brazilian Expeditions to Antarctica I-IX (1982-1991). The bivalves collected in the Western Antarctic and Subantarctic waters by scientists of the Instituto Oceanográfico - USP during the Scientific Brazilian Expeditions to Antarctica I-IX are characterised through its conchiliological features, illustrated and their occurrence plotted in maps. A species of bivalve collected by scuba divers of the IO-USP on the Napier Rock, Admiralty Bay, King George Island during the Expeditions XV and XVI is also considered in this work. The material identified is representative of 25 species distributed among three families and four genera of Protobranchia, three families and five genera of Pteriomorpha, five families and six genera of Heterodonta, and four families and four genera of Anomalodesmata. The main scope of this work is to provide searchers dealing with macrobenthic fauna with an ease identification guide to the bivalved molluses of the sampled region.

KEY WORDS. Bivalvia, Mollusca, Antarctic, Subantarctic, taxonomy
\end{abstract}

A implementação, em 1982, do Programa Antártico Brasileiro (PROANTAR) e a aceitação do Brasil como parte Consultiva do Tratado Antártico vieram estimular novas linhas de pesquisa em instituições brasileiras.

As Expedições Científicas Brasileiras à Antártica (Operações Antártica I a IX) realizadas de 1982 a 1991 incluíram projeto de levantamento e reconhecimento da fauna bentônica, conduzido por equipes de pesquisadores do Instituto Oceanográfico da Universidade de São Paulo (IO-USP) a bordo do N/Oc. "Prof. W. Besnard" e em atividades de mergulho autônomo. O projeto, iniciado com a Operação Antártica IV (1986), foi precedido de amostragens esporádicas em Operações anteriores (NONATO et al. 1992a). Das Operações VI a IX as atividades desse projeto concentraram-se no estudo da fauna bentônica da Baía do Almirantado, Ilha Rei George (NONATO et al. 1992b), onde está instalada, desde 1984, a Estação Antártica Brasileira "Comandante Ferraz" (EACF).

A identificação dos bivalves coletados nessas expedições foi confiada aos autores do presente trabalho que se defrontaram com escassa bibliografia especializada presente em bibliotecas brasileiras, e com a ausência de material biológico sobre a fauna antártica e subantártica em museus científicos nacionais.

1) Departamento de Zoologia, Instituto de Biociências, Universidade de São Paulo.

Caixa Postal 11461, 05422-970 São Paulo, São Paulo, Brasil.

Revta bras. Zool. 19 (3): 645 - 675, 2002 
Muitas das publicações existentes estão em bibliotecas no exterior e se constituem de monografias extensas elaboradas a partir da segunda metade do século XIX, trazendo relatos e resultados de expedições de diversos países às regiões antártica e subantártica. As principais publicações que tratam dos moluscos da fauna bentônica antártica e subantártica foram compiladas por DELL $(1964,1972)$. Esse autor comentou sobre as dificuldades de reunião dessas publicações, de sua análise, e da sistematização dos conhecimentos obtidos até então sobre os moluscos, devido em parte à diversidade de línguas em que os trabalhos foram redigidos e à diversidade de publicações científicas onde estão inseridos. Além dos trabalhos de DELL (1964, 1972), os de SoOT-RYEN (1951), Powell (1960, 1965), Nicol (1966, 1967, 1970), ARNAud (1973, 1974) e Dell (1990) destacam-se na abordagem dos moluscos, sendo de consulta obrigatória para a compreensão da evolução dos conhecimentos sobre a fauna dessas regiões.

$\mathrm{O}$ número restrito de publicações em bibliotecas nacionais sobre a fauna antártica e subantártica dificulta ao pesquisador brasileiro a identificação dos bivalves daquelas regiões. A ocorrência de descrições originais insuficientes pela falta de detalhes relativos à charneira e/ou de ilustrações adequadas, mais os freqüentes entraves de ordem taxonômica aumentam essas dificuldades, mesmo para os especialistas no grupo. Minimizar esses problemas e possibilitar aos interessados o rápido reconhecimento dos bivalves e respectivos locais de ocorrência na região amostrada pelas Operações Antárticas I a IX são os objetivos do presente trabalho, elaborado sob a forma de um guia ilustrado. Este inclui uma espécie coletada no Rochedo Napier, Baía do Almirantado, em atividades de mergulho durante as Operações XV e XVI.

Os autores não entram no mérito, tampouco registram a evolução das discussões de ordem taxonômica que envolvem muitas das espécies identificadas, uma vez que esses aspectos são abordados principalmente nas obras de POWELL (1960), Dell (1964, 1990) e NiCOL (1966).

\section{Área amostrada e metodologia}

Nas Operações Antártica I a V (1982 a 1987) as amostragens foram feitas na região das Ilhas Shetland do Sul e dos Estreitos de Bransfield e Gerlach, entre os paralelos $60^{\circ} \mathrm{e} 65^{\circ} \mathrm{S}$. As coletas foram realizadas em profundidades de 17 a 520 metros, utilizando-se draga "Beam-Trawl", pegadores de fundo "Van Veen", redes de arrasto "Otter-Trawl" e armadilhas (NONATO et al. 1992a). A partir da VI Operação foram implementadas as atividades de mergulho autônomo, durante as quais foram recolhidas amostras da fauna bentônica em profundidades de 6, 11, 18 e 25 metros com testemunhadores cilíndricos ("corers"), ao longo de uma radial em frente à EACF (NONATO et al. 1992b). Na VII Operação Antártica não houve coleta de bentos.

As condições físicas, as coordenadas geográficas das regiões e das respectivas estações de origem dos bivalves coletados pelas Operações Antártica I a IX estão registradas em tabelas publicadas por NONATO et al. (1992a, b). Nesses mesmos trabalhos os autores descreveram os materiais, a metodologia de coleta e apresentaram um relato de cada expedição, acrescentando nas tabelas os dados de temperatura, salinidade, profundidade e tipo de sedimento referentes a cada coleta de bentos. 
Mergulhos exploratórios para avaliar as possibilidades de trabalho ao redor do Rochedo Napier, Baía do Almirantado, bem como sobre as comunidades aí existentes foram realizados durante a VI Operação Antártica. Embora bivalves não tenham sido coletados nesse local e nessa Operação específica, uma espécie com populações numerosas foi detectada a partir de coletas nesse rochedo durante as Operações Antártica XV e XVI. Essa espécie é incluída no presente trabalho, visando abranger o maior número de bivalves da Baía do Almirantado.

Na figura 1 estão assinaladas as posições das estações de coleta no Estreito de Bransfield e áreas adjacentes durante as seis primeiras expedições, e nas figuras 2 e 3 os pontos amostrados no interior da Baía do Almirantado.

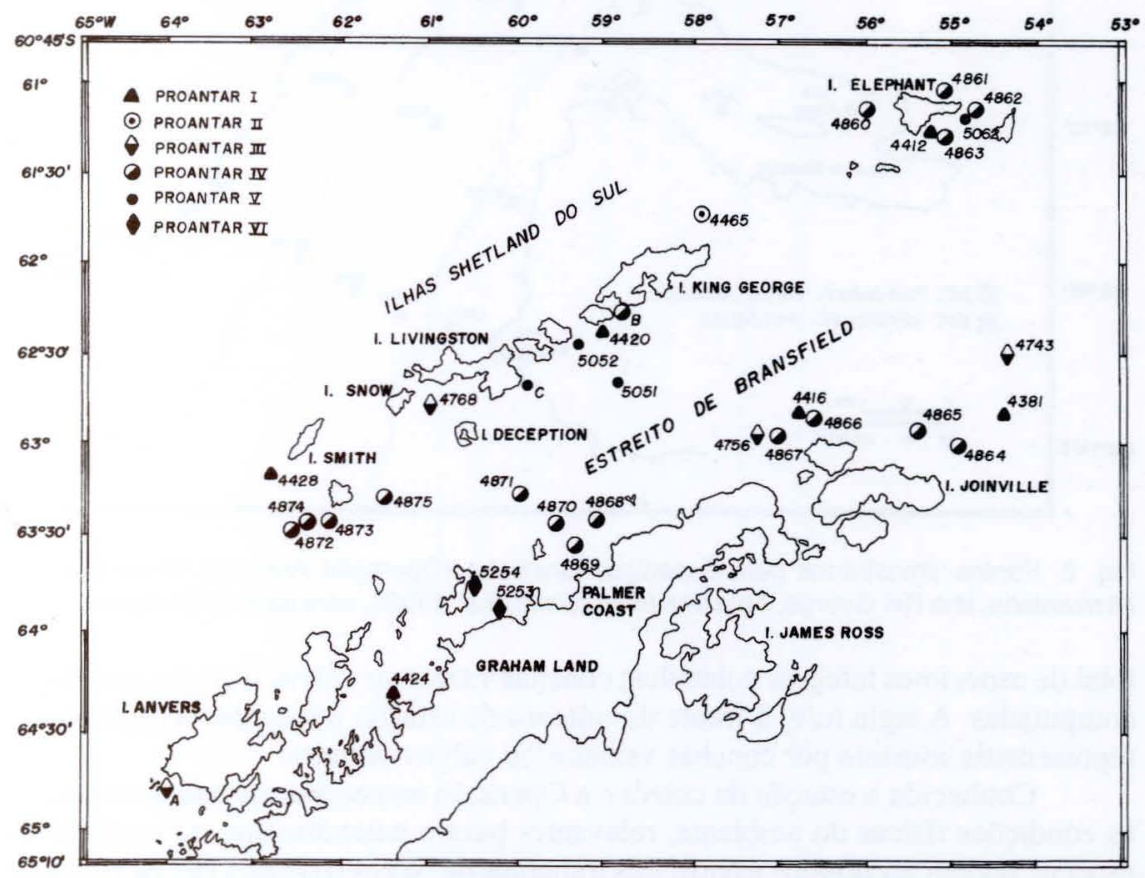

Fig. 1. Posição das estações de coleta das Expedições Brasileiras (Operações Antárticas I a VI). (de NonATo et al. 1992a, com permissão dos autores).

Os bivalves, preservados em álcool a 70\%, foram incorporados ao acervo do Laboratório de Malacologia do Instituto de Biociências da Universidade de São Paulo (IB-USP), onde continuam sendo estudados sob os aspectos taxonômico e morfológico.

Cada espécie é identificada por ilustração original e descrição detalhada das características da concha, incluindo-se o comprimento do maior exemplar existente nas amostras. É acrescentada a referência bibliográfica onde ocorreu a descrição original da espécie, bem como a Expedição e respectivas estações em que foi encontrada. O número entre parênteses à frente de cada estação de coleta indica o 


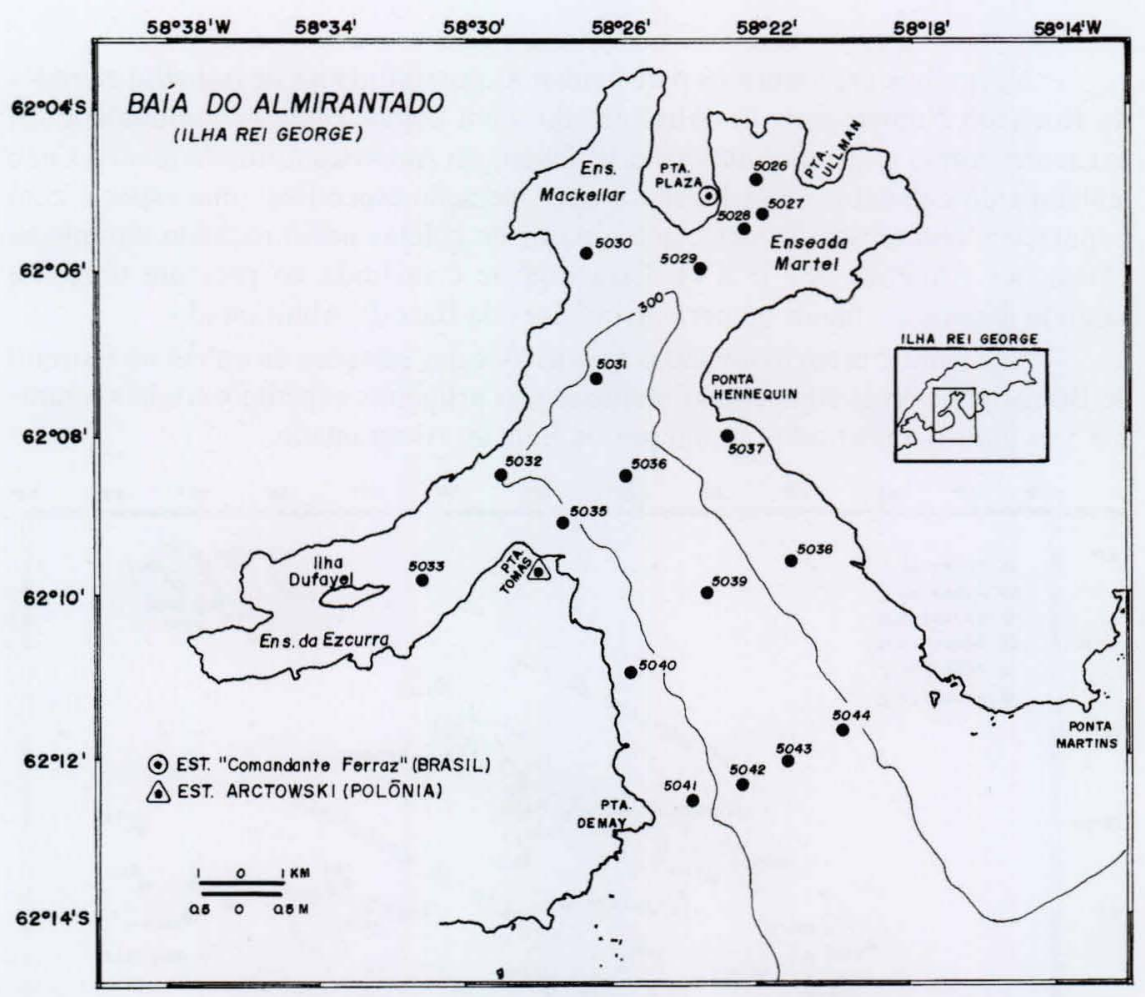

Fig. 2. Pontos amostrados pela Expedição Brasileira (Operaçāo Antártica V) na Baía do Almirantado, Illha Rei George, Antártica (de NonATo et al. 1992a, com permissão dos autores).

total de espécimes íntegros coletados; conchas vazias ou valvas isoladas não foram computadas. A sigla (c/v) à frente do número da estação indica que a espécie está representada somente por conchas vazias e/ou valvas isoladas.

Conhecida a estação de coleta e a Operação respectiva, os dados referentes às condições físicas do ambiente, relevantes para o entendimento da ecologia da espécie, podem ser obtidos a partir dos trabalhos de NONATO et al. (1992a, b), razão pela qual não foram informados no presente trabalho.

A ilustração e a caracterização de cada espécie foram elaboradas a partir do material biológico depositado no acervo do Laboratório de Malacologia do IB-USP. Para a caracterização das espécies reuniu-se informações presentes na literatura, complementando-a. Para algumas das espécies a caracterização detalhada, complementando a descrição original, é exclusiva dos autores.

A classificação adotada para os Protobranchia é a de VILLARROEL \& STUARDO (1998) e para os demais Bivalvia a de COAN et al. (2000). A distribuição geográfica é baseada em Villarroel \& STUARDO (1998), NiCOL (1966) e DELL (1990).

As ilustrações a nanquim estão assinadas pelos respectivos desenhistas e são, na sua maioria, do artista plástico Ricardo Cavani Rosas; as fotos são originais dos autores. 


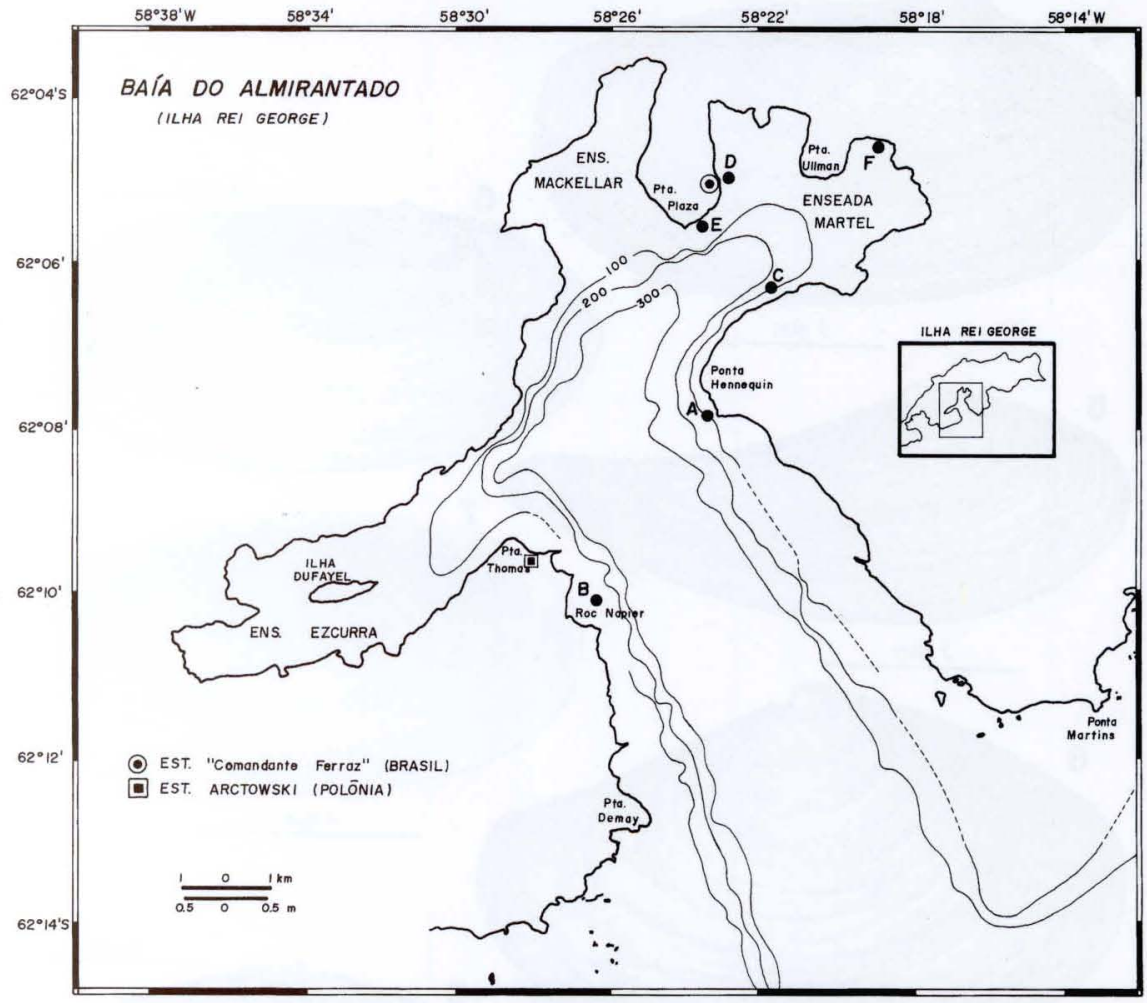

Fig. 3. Pontos amostrados pelas Expedições Brasileiras (Operações Antárticas VI, VIII e IX) na Baía do Almirantado, Ilha Rei George, Antártica (de NonATo et al. 1992b, com permissão dos autores).

\section{RESULTADOS}

\section{Subclasse Protobranchia}

Nuculanidae H. Adams \& A. Adams, 1858

Nuculana Link, 1807

\section{Nuculana inaequisculpta (Lamy, 1906) (Figs 4, 42)}

Yoldia inaequisculpta Lamy, 1906b: 125, fig. 3.

Concha oval, semirretangular (maior exemplar $=16 \mathrm{~mm}$ de comprimento), branca, com umbos anteriores subcentrais; margem anterior uniformemente arredondada e posterior truncada obliquamente. Perióstraco liso, brilhante, variando do amarelo claro que deixa transparecer o branco da concha em espécimes pequenos a medianos, até o amarelo-esverdeado, principalmente entre os indivíduos de maior tamanho. Ornamentação constituída por costelas baixas, arredondadas, com interespaços irregulares; costelas mais evidentes na região central, diminuindo nas regiões anterior e posterior que são quase lisas. Áreas dorsais anterior e posterior elevadas e finamente sulcadas pela continuação das costelas concêntricas que se dirigem até os 


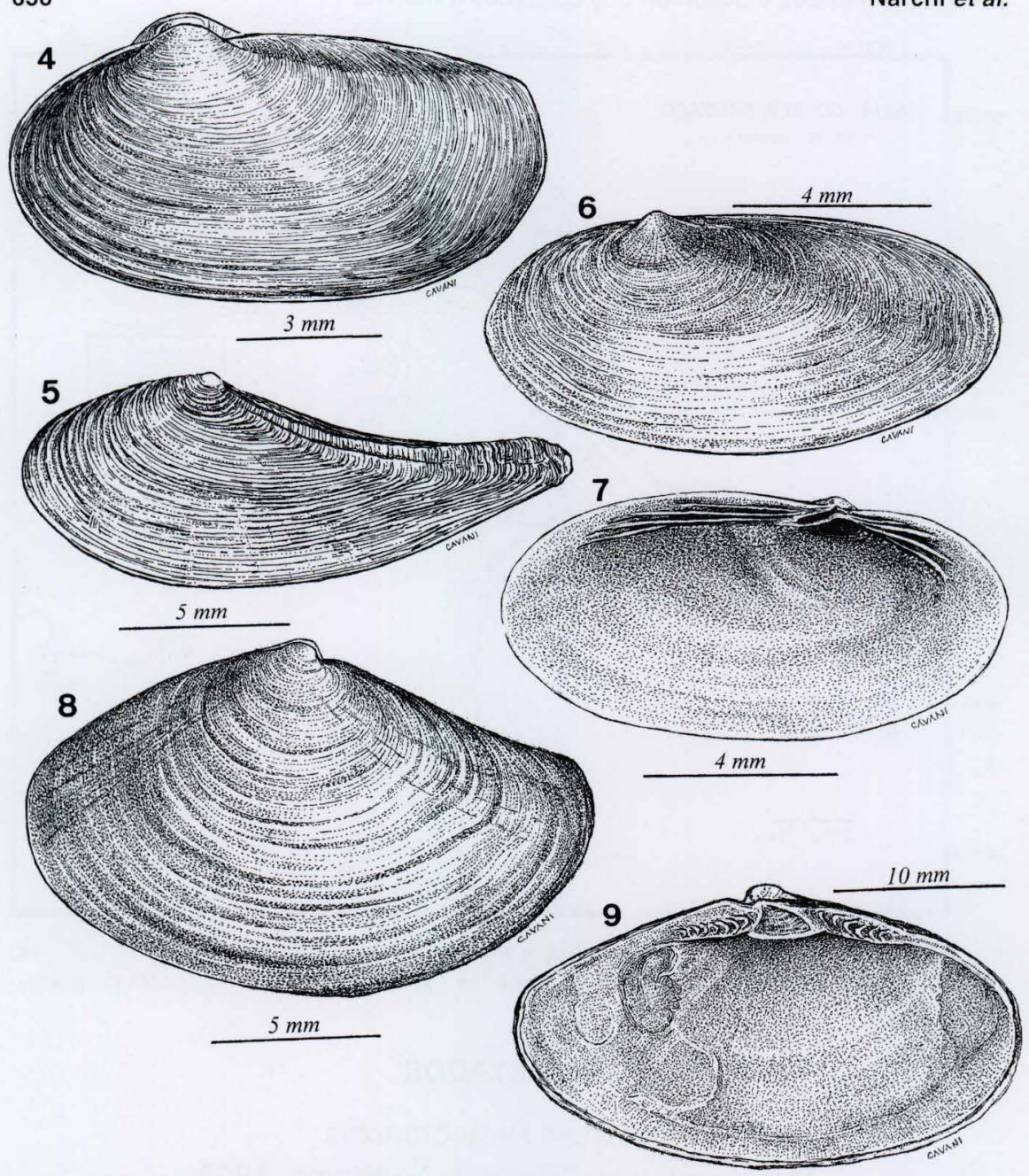

Figs 4-9. Concha vista pela valva esquerda: (4) Nuculana inaequisculpta, (5) Propeleda longicaudata, (6) Silicula rouchi, (8) Yoldia eightsi. Valva esquerda em vista interna: (7) $S$. rouchi, (9) Y. eightsi.

umbos. Finas linhas de crescimento são visíveis por toda a superfície da concha. Charneira taxodonte, com muitos dentes em forma de "V", elevados, com base larga, pontiagudos, variando em número com o crescimento do animal. Ligamento predominantemente interno, forte, anfidético, preso a um condróforo em cada valva.

[Operação] - Estações de coleta: [II] - "Ferraz"(c/v); [IV] - 4864(12), 4869(39); [V] - 5026(27), 5027(33), 5029(10), 5031(03), 5032(01), 5036(02), 5039(04), 5044(09), 5052(09).

Distribuição: Orcadas do Sul, Shetland do Sul, Geórgia do Sul, Arquipélago de Palmer, Estreito de Bransfield, Baia Rybiy Khvost, Oceano Índico (Antártica), em profundidades de 48 a 160 m (VILLARROEL \& STUARDO 1998). 


\section{Propeleda Iredale, 1924 \\ Propeleda longicaudata (Thiele, 1912)}

Fig. 5

Leda longicaudata Thiele, 1912: 229, pl. 17, fig. 22.

Concha alongada (maior exemplar $=26 \mathrm{~mm}$ de comprimento), frágil, equivalve, inequilateral, fortemente comprimida nos exemplares pequenos. Umbos inconspícuos, ligeiramente opistógiros. Região anterior aos umbos curta, com margem arredondada, e região posterior extensa, com rostro longo e estreito, arqueando em direção dorsal. Declive dorsal posterior com duas quilhas que se estendem em cada valva a partir do umbo e se separam gradualmente até alcançarem a margem posterior. Essas quilhas têm como equivalentes no interior da concha, uma ou duas costelas que se prolongam em direção posterior, a ventral tornando-se mais elevada na região mediana do rostro. Perióstraco fino, fosco, castanho claro esverdeado. Lúnula alongada, com numerosas estrias oblíquas muito finas. Ornamentação constituída por costelas concêntricas, estreitas, lisas e baixas, que se tornam menos evidentes em direção à margem ventral e mudam abruptamente de direção ou mesmo desaparecem à medida que cruzam as quilhas dorsais. Charneira taxodonte, com numerosos dentes laminares alongados, cuja série posterior é quase o dobro da anterior. Ligamento predominantemente interno, alojado num resilífero sob o umbo e prolongando-se em direção posterior. Cicatrizes musculares pouco conspícuas.

[Operação] - Estações de coleta: [I] - 4381(01); [IV] - 4863(c/v), 4864(02), 4869(26), 4872(01), 4875(01); [V] - 5036(03), 5052(01).

Distribuição: circum-antártica, Península Antártica até Shetland do Sul, Orcadas do Sul, em profundidades de 64 a 1180 m (DELL 1990).

\section{Siliculidae Allen \& Sanders, 1973 Silicula Jeffreys, 1879}

\section{Silicula rouchi Lamy, 1910}

Figs 6,7

Silicula rouchi Lamy, 1910: 394.

Concha oblonga (maior exemplar $=12 \mathrm{~mm}$ de comprimento), muito frágil, comprimida, equivalve e entreaberta anteriormente. Umbos pequenos, pouco proeminentes, localizados no terço anterior. Margem anterior da concha arredondada e posterior subtruncada; margens dorsais anterior e posterior retas e ventral ampla e arqueada. Perióstraco liso, brilhante, amarelo-esverdeado e iridescente. Ornamentação por linhas de crescimento finas e muito próximas. Charneira com dentes lamelares alongados, irradiando do umbo para as regiões anterior e posterior, e mantendo-se paralelos à margem dorsal da valva. Ligamento quase totalmente interno, alojado em um resilífero oblíquo que se prolonga a partir do umbo para a região posterior. Superfície interna da concha com cicatrizes musculares pouco visíveis. 
[Operação] - Estações de coleta: [IV] -4863(c/v), 4869(05); [V] - 5036(01), 5044(01), 5052(01).

Distribuição: circum-antártica e se estendendo pela Península Antártica até Shetland do Sul, Orcadas do Sul e Geórgia do Sul, em profundidades de 160 a 836 m (DELL 1990)

\section{Sareptidae Stoliczka, 1871 \\ Yoldia Möller, 1842 \\ Yoldia eightsi (Couthouy, 1839 in Jay)}

Figs 8,9

Nucula eightsii Couthouy, 1839 in Jay: 113, pl. 1, figs 12, 13 .

Concha suboval (maior exemplar $=32 \mathrm{~mm}$ de comprimento), comprimida, mais entreaberta na extremidade anterior. Região posterior ligeiramente estreitada e angulosa, comparativamente à região anterior uniformemente arredondada. Umbos opistógiros, subcentrais posteriores, pequenos, pouco pronunciados e freqüentemente erodidos. Margem dorsal posterior levemente, ou por vezes acentuadamente côncava e margem ventral uniformemente arqueada. Perióstraco brilhante, amarelo-esverdeado nas formas juvenis e marrom-esverdeado escuro nos espécimes de tamanho maior. Ornamentação constituída por finas linhas de crescimento e estrias radiais mais evidentes próximas aos declives anterior e posterior. Charneira taxodonte, com duas séries subiguais, curtas, de dentes fortes em forma de "V". Ligamento quase totalmente interno e fosseta ligamentar triangular grande. Face interna da concha ligeiramente azulada, principalmente nas margens. Seio palial profundo, estendendo-se até o nível da fosseta ligamentar.

[Operação] - Estações de coleta: [I] - 4412(11), 4420(01); [II] - "Ferraz" (22); [V] - 5026(13), 5036(01); [VI] - D(4); [VIII] - radial em frente à EACF(97); [IX] - radial em frente à $\operatorname{EACF}(48)$.

Distribuição: provável distribuição circum-antártica, Shetland do Sul, Orcadas do Sul, Ilhas Sandwich do Sul, Geórgia do Sul, Ilhas Falkland, Terra do Fogo, sul do Chile e Ilha Kerguelen, de 4 a 824 m de profundidade (DELL 1990).

\section{Subclasse Pteriomorphia \\ Limopsidae Dall, 1895 \\ Limopsis Sassi, 1827}

\section{Limopsis marionensis Smith, 1885}

Fig. 10

Limopsis marionensis Smith, 1885: 254, pl. 18, figs 2, 2 b.

Concha comprimida, obliquamente ovalada ou obliquamente circular (maior exemplar $=54 \mathrm{~mm}$ de comprimento), fina, equivalve e inequilateral. Umbos ortógiros, pequenos, próximos, localizados no terço anterior e freqüentemente erodidos nos exemplares de tamanho mediano a grande. Perióstraco nos maiores espécimes muito desenvolvido, castanho-dourado, com cerdas finas, moderadamen- 

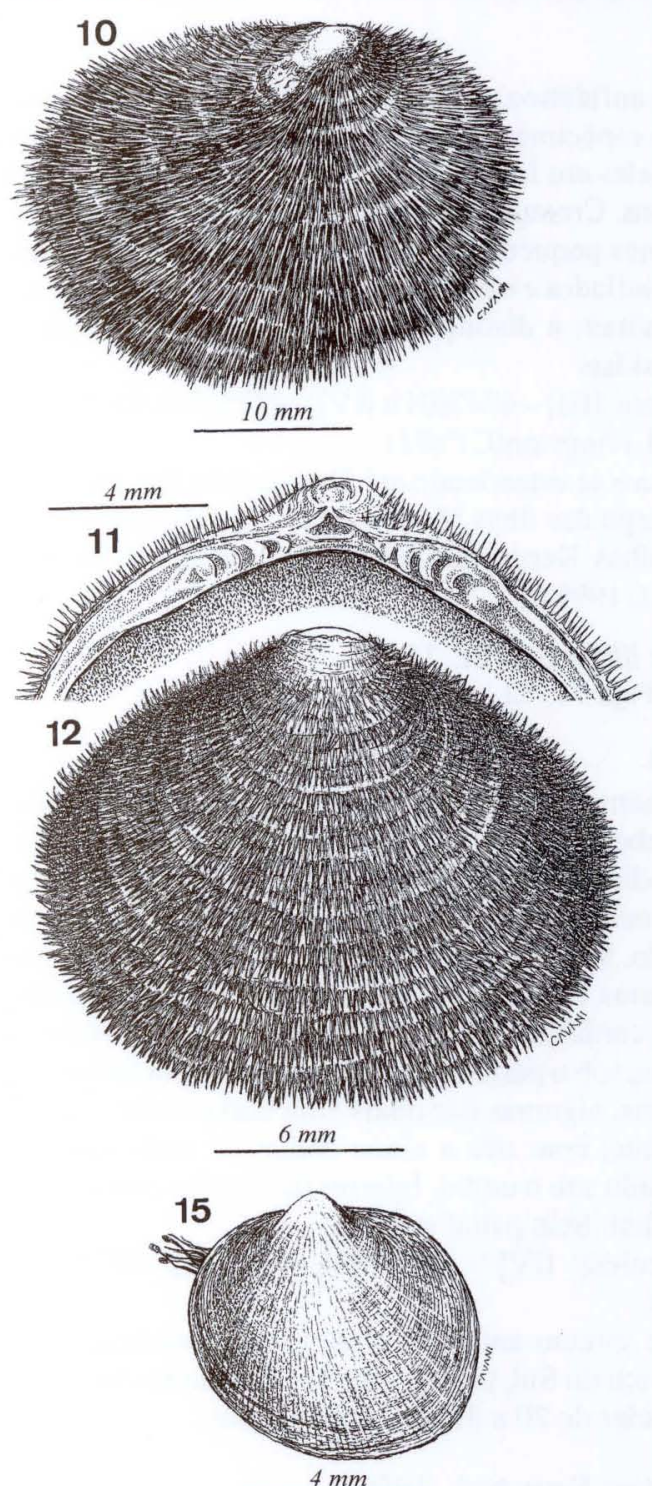

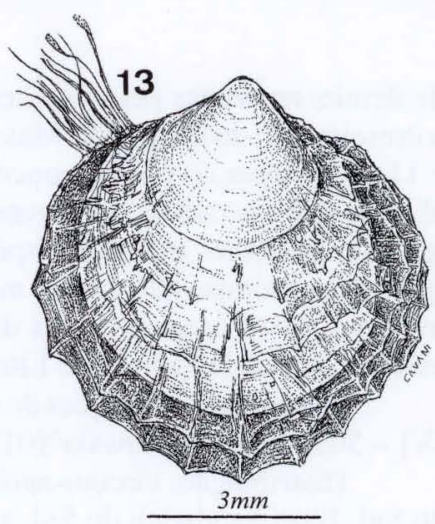

14

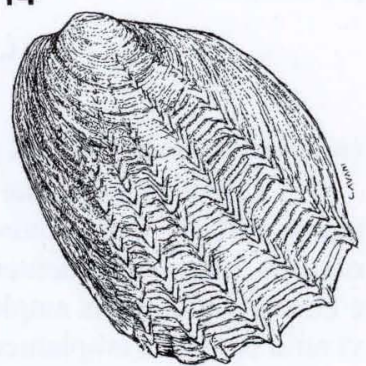

$2 \mathrm{~mm}$

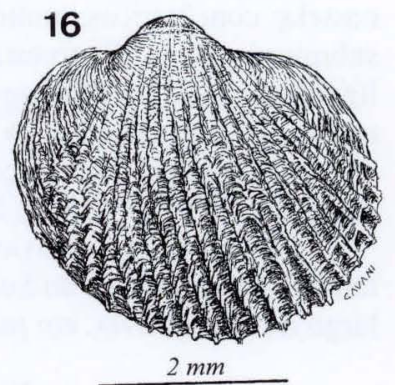

Figs 10-16. Concha vista pela valva direita: (10) Limopsis marionensis. Concha vista pela valva esquerda: (12) Limopsis lilliei, (13) Philobrya sublaevis, (14) Philobrya wandelensis, (15) Adacnarca nitens, (16) A. limopsoides. Detalhe da charneira da valva esquerda: (11) L. lilliei.

te longas e imbricadas. Espécimes medianos com perióstraco fino e pilosidade menos abundante, com arranjo radial típico. Espécimes pequenos com perióstraco pouco conspícuo. Quando o perióstraco é fino, ou quando removido da valva, sobre esta é visível uma ornamentação delicada, de padrão subcancelado próximo ao umbo e concêntrico em direção à periferia da concha. Charneira taxodonte, com duas séries 
de dentes separadas pelo ligamento anfidético, e dentes variando em número com o crescimento do exemplar. Maiores espécimes apresentam até 13 dentes anteriores e 11 posteriores ao umbo, poucos deles em forma de "V". Interior da concha com algumas estrias radiais e margens lisas. Crenulações marginais podem estar presentes nos espécimes maiores. Espécimes pequenos têm altura e comprimento quase iguais e são comparativamente mais inflados e menos assimétricos que os espécimes maiores. Essas características dificultam a distinção dessa espécie em relação a outras espécies antárticas de Limopsidae.

[Operação] - Estações de coleta: [III] - 4743(01); [IV] - 4872(01), 4875(03); [V] - 5052(01), "Arctowski"(01), "Livingston(C)"(01).

Distribuição: circum-antártica e se estendendo até Shetland do Sul, Orcadas do Sul, Ilhas Sandwich do Sul, ao largo das ilhas Marion, Príncipe Edward, região Magelânica, Ilhas Falkland, entre ilhas Kerguelem e Heard, e sul do Chile, em profundidades de 27 a 1674 m (DELL 1990).

\section{Limopsis lilliei Smith, 1915}

Figs 11, 12

Limopsis lilliei Smith, 1915: 76, pl. 1, fig. 18.

Concha subcircular (maior exemplar $=17 \mathrm{~mm}$ de comprimento), moderadamente inflada, fina, equivalve e subequilateral. Umbos ortógiros, submedianos, obtusos, baixos, freqüentemente erodidos. Região anterior ligeiramente mais curta e com margem mais ampla e arredondada comparada à região posterior. Margem ventral convexa, amplamente arcuada. Margens internas lisas. Perióstraco castanho amarelado, espesso, com cerdas curtas e finas, em séries concêntricas e radiais. Algumas das séries radiais possuem cerdas mais largas e longas que as das séries a elas interpostas. Superfície da concha, sob o perióstraco, ornamentada por inúmeras costelas concêntricas, muito próximas, algumas das quais com certa nodulosidade submicroscópica. Charneira taxodonte, com três a cinco dentes de cada lado do ligamento anfidético, alongado, situado sob o umbo. Interior da concha com estrias radiais finas terminando na linha palial. Seio palial ausente.

[Operação] - Estações de coleta: [IV] - 4864(06), 4869(05), 4872(07), 4874(02); [V] - 5027(04), 5052(01).

Distribuição: provavelmente circum-antártica, Península Antártica, Shetland do Sul, Orcadas do Sul, Sandwich do Sul, Geórgia do Sul, Rochedos Shag, ao largo da Ilha Bouvet, em profundidades de 20 a 870 m (DELL 1990).

\section{Philobryidae Bernard, 1897 \\ Philobrya Carpenter, 1872}

\section{Philobrya sublaevis Pelseneer, 1903}

Fig. 13

Philobrya sublaevis Pelseneer, 1903: 25, 26, 42, 43, pl. 7, figs 93, 94.

Concha subpiriforme, branca a verde-pálido, fina, algo translúcida, com altura geralmente maior que o comprimento (maior exemplar $=13 \mathrm{~mm}$ de comprimento). Umbos ortógiros, submedianos e próximos. Margem dorsal anterior e 
posterior aos umbos quase retas e acentuadamente inclinadas, conferindo à região umbonal um perfil fortemente anguloso. Margens anterior, posterior e ventral arredondadas. Abertura de passagem do bisso pequena, anterior aos umbos na área lunular. Concha nepiônica quase sempre presente, com ornamentação radial granulosa submicroscópica e com bordas salientes marcando a transição para a dissoconcha. Perióstraco muito desenvolvido, translúcido, formando lâminas concêntricas, elevadas e se sobrepondo parcialmente. Perióstraco melhor preservado próximo e na periferia da concha, onde lâminas concêntricas se prolongam para além da margem das valvas. Lâminas do perióstraco com costelas variando em número de 15 a 25, alinhadas às costelas de lâminas adjacentes, conferindo ornamentação radiada à superfície periostracal. Removido o perióstraco, a superfície da concha revela ornamentação de aspecto cancelado devido a presença de linhas concêntricas e estrias radiais elevadas, as últimas correspondendo em posição às costelas do perióstraco. Charneira edêntula; ligamento opistodético, alongado, estreito e preso a um longo sulco embutido numa área plana similar a uma placa de charneira. Essa área tem uma extensão anterior arredondada terminando na extremidade anterior do umbo. Interior da concha liso ou fracamente estriado radialmente, e margem livre com fracos dentículos, nem sempre presentes em conchas erodidas; linha palial e cicatrizes musculares não visíveis.

[Operação] - Estações de coleta: [IV] - 4866(05), 4868(02), 4869(01), 4870(01), 4872(05); [V] - 5026(01), 5033(c/v), 5036(02), 5052(02), 5062(01), "Livingston(C)"(01).

Distribuição: circum-antártica, estendendo-se até a Península Antártica, Shetland do Sul, Orcadas do Sul, Ilhas Sandwich do Sul, Geórgia do Sul e Ilhas Bouvet, em profundidades de 1 a 923 m (DELL 1990).

\section{Philobrya wandelensis Lamy, 1906}

Figs 14, 43

Philobrya wandelensis Lamy, 1906a: 50, fig. 4.

Concha modioliforme, oval-subquadrangular, branca, pequena (maior exemplar $=3,5 \mathrm{~mm}$ de comprimento), inequilateral e de altura maior que o comprimento. Umbos ortógiros, contíguos, situados no quarto anterior da margem dorsal. Margem dorsal retilínea, inclinada em direção posterior e ventral. Margem anterior alta, quase reta arqueando abruptamente na confluência com a margem dorsal anterior curta; margem posterior mais curta que a anterior, ligeiramente convexa e margem ventral convexa. Perióstraco laminar, comumente marrom-amarelado, ultrapassando a borda das valvas, especialmente na margem ventral. Lâminas do perióstraco com cerca de cinco costelas radiais fracas, alinhadas às das lâminas adjacentes e se tornando mais proeminentes em direção à borda ventral. Costelas do perióstraco ausentes nos declives anterior e posterior da concha. Superfície da valva sob o perióstraco ornamentada por fracas costelas radiais, cruzadas por numerosas estrias concêntricas e por poucas, espaçadas e fracas costelas igualmente concêntricas. Estas últimas nem sempre presentes. Charneira retilínea, edêntula, estendendo-se de ambos os lados do sulco ligamen- 
tar como uma placa estreita, finamente estriada transversalmente. Porção posterior da charneira cerca de duas vezes mais longa que a anterior. Ligamento opistodético, parcialmente externo e com a porção interna presa a um sulco ligamentar moderadamente profundo, alongando-se em direção posterior a partir do umbo. Superfície interna lisa e com poucas crenulações denticulares na margem posterior.

[Operação] - Estações de coleta: [IV] - 4870(02); [V] - 5027(01), 5029(03), 5033(01).

Distribuição: provavelmente circum-antártica, Península Antártica, Shetland do Sul, ao longo do Arco Escócia até Orcadas do Sul, Ilhas Sandwich do Sul, Geórgia do Sul e Banco Burdwood, em profundidades de 5 a 870 m (DELL 1990).

\section{Adacnarca Pelseneer, 1903}

\section{Adacnarca nitens Pelseneer, 1903}

Figs $15,45,46,47$

Adacnarca nitens Pelseneer, 1903: 24, 41, 42, pl. 7, figs 83, 84, 85, 86, 87, 88 .

Concha moderadamente globosa, pequena (maior exemplar $=5 \mathrm{~mm}$ de comprimento), fina, semitransparente. Espécimes menores comumente orbiculares e maiores obliquamente arredondados, algo alongados em direção pósteroventral. Margem livre interna da concha com crenulações denticulares. Umbos ortógiros, contíguos, situados no centro da margem dorsal curta, praticamente retilínea, inclinando-se suavemente em direção posterior; margens anterior, posterior e ventral uniformemente arredondadas, a posterior mais alta que a anterior. Perióstraco raramente preservado, muito fino, castanho claro ou esverdeado. Superfície externa brilhante ou mesmo perlácea, lisa, a não ser pela presença de numerosas costelas radiais finas, não discerníveis em alguns espécimes. Até quatro linhas de crescimento são verificadas nos maiores espécimes. Charneira edêntula, ligeiramente arqueada, com margem dorsal das áreas anterior e posterior ao ligamento com estriações transversais microscópicas, perpendiculares à margem dorsal. Porção principal do ligamento fixa a uma depressão triangular rasa, sob os umbos, e pequena porção se estendendo a uma curta distância de cada lado da principal. Superfície interna da concha com perfurações microscópicas ou aberturas de microtúbulos que se aprofundam pela parede das valvas e aparentemente não atingem a superfície externa. Visualizados externamente através da semi-transparência da concha, esses microtúbulos simulam ornamentação por numerosíssimos fios excessivamente finos e curtos. Superfície interna da concha com cicatrizes musculares indistintas na maioria dos espécimes.

[Operação] - Estações de coleta: [III] - 4743(01); [IV] - 4864(04), 4868(03), 4872(11), 4873(03), 4874(05); [V] - 5031(01), 5041(01).

Distribuição: circum-antártica, estendendo-se até Shetland do Sul, Orcadas do Sul, Ilhas Sandwich do Sul e Geórgia do Sul, em profundidades de 8 a 2.350 m (DELL 1990). 


\section{Adacnarca limopsoides (Thiele, 1912) \\ Figs 16,44}

Hochstetteria limopsoides Thiele, 1912: 227, 228, pl. 7, figs 13, 13a.

Concha moderadamente globosa, fina, pequena (maior exemplar $=3 \mathrm{~mm}$ de comprimento), opaca, equivalve. Contorno obliquamente arredondado, algo alongado em direção póstero-ventral; altura e comprimento similares. Umbos ortógiros, subcentrais anteriores; área umbonal algo inflada, com prodissoconcha de margem dorsal reta, as demais simetricamente arredondadas e sobressaindo-se sobre a dissoconcha. Prodissoconcha ornamentada com estrias radiais evidentes e fraca ornamentação concêntrica no declive posterior. Dissoconcha com margem dorsal reta, inclinada suavemente em direção posterior; margens anterior, posterior e ventral uniformemente arredondadas, a posterior mais alta que a anterior. Perióstraco espesso, castanho pálido, de aspecto lamelar, espinhoso, projetando-se além das margens da concha, com exceção da dorsal. Projeções espinhosas do perióstraco alinhadas, coincidentes com as estrias radiais na superfície da dissoconcha. Superfície externa da dissoconcha sem linhas de crescimento, mas com ornamentação de aspecto cancelado, constituída por muitas estrias concêntricas elevadas, muito próximas, e numerosas estrias radiais, comparativamente bem espaçadas. Charneira edêntula, com margem dorsal das áreas anterior e posterior ao ligamento com estriações transversais microscópicas, perpendiculares, mais alongadas na área posterior. Porção principal do ligamento fixa a uma depressão rasa, subtriangular, sob o umbo. Parte do ligamento estende-se a curta distância de ambos os lados a partir da porção principal do ligamento. Margem livre das valvas com campo de crenulações denticulares fortes nas margens anterior e posterior, e fraca na margem ventral, esta última isolada das precedentes por hiatos edêntulos. Superfície interna da concha com cicatrizes musculares indistintas.

[Operação] - Estações de coleta: [V] - 5029(02), 5031(01).

Distribuição: de $54^{\circ} \mathrm{E}$ no continente antártico até o Mar de Ross, e a $13^{\circ} \mathrm{W}$ ao largo da Shetland do Sul e no Estreito de Bransfield, em profundidades de 110 a $523 \mathrm{~m}$ (DELL 1990).

\section{Lissarca Smith, 1877}

\section{Lissarca miliaris (Philippi, 1845)}

Figs 17, 18, 19

Pectunculus miliaris Philippi, 1845: 56.

Concha obliquamente oval-subquadrada, muito pequena (maior exemplar $=5$ mm de comprimento), inflada, equivalve, inequilateral. Umbos ortógiros, arredondados, pouco proeminentes, situados na metade anterior da concha. Prodissoconcha rosada, com margem dorsal reta. Coloração externa da dissoconcha violácea-esbranquiçada no material seco e castanha-violácea no material recém-coletado. Margem anterior arredondada e margem posterior subtruncada mais alta; margem ventral ligeiramente convexa. Perióstraco fino, deiscente, de coloração castanha, brilhante, melhor preservado na periferia da concha. Escultura constituída por estrias concêntri- 

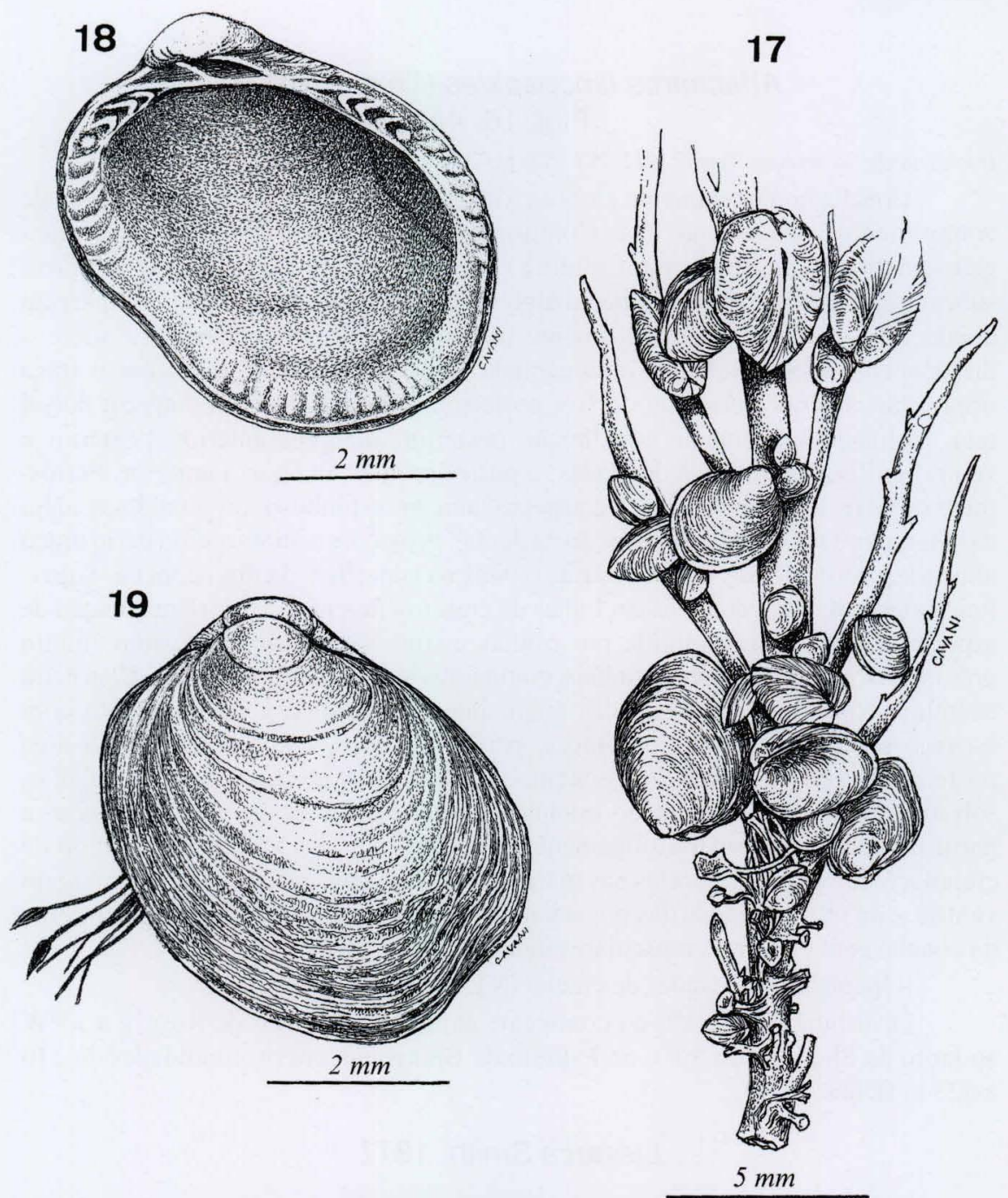

Figs 17-19. Lissarca miliaris: (17) espécimes fixos pelo bisso a um ramo de alga Phaeophycea, (18) vista interna da valva direita, (19) concha vista pela valva esquerda.

cas, com freqüente adição de estrias radiais fracas, particularmente na metade posterior da concha. Charneira taxodonte, arqueada, com ligamento parcialmente externo, anfidético, e resílio implantado num resilífero central, iniciando sob o umbo e alongando-se em direção posterior. Dentes proeminentes, os maiores em forma de "V". Série anterior com três e série posterior com três a quatro dentes, ambas separadas por longo hiato edêntulo. Margem interna com três campos de crenulações denticulares, um adjacente à série anterior, outro adjacente à série posterior de dentes da charneira, e um terceiro situado na margem ventral. Interior da concha de cor esbranquiçada na periferia e castanha-arroxeada nos limites internos à linha palial. 
[Operação] - Estações de coleta: [XV e XVI - ver Material e Métodos] "Rochedo Napier" $(n>1000)$.

Distribuição: região Magelânica, Geórgia do Sul, Orcadas do Sul, Shetland do Sul e Península Antártica, em profundidades de 0 a 265 m (DELl 1990).

\section{Lissarca notorcadensis Melvill \& Standen, 1907}

Figs 20, 21, 22

Lissarca notorcadensis Melvill \& Standen, 1907: 144, figs 14, 14a.

Concha oval-trapezóide, branca, pequena (maior exemplar $=5 \mathrm{~mm}$ de comprimento), espessa, equivalve, inequilateral. Umbos obtusos, arredondados. Contorno pode variar em decorrência da concentração de indivíduos que disputam pelo espaço para fixação. Perióstraco amarelado, fino, deiscente, melhor preservado na periferia. Superfície ornamentada por estrias concêntricas. Alguns espécimes apresentam costelas radiais na face interna da concha, particularmente nas regiões anterior e posterior, visíveis devido a semi-transparência da concha. Charneira taxodonte, fracamente arqueada. Dentes proeminentes, os maiores em forma de "V", quatro a cinco (mínimo dois, máximo seis) nas séries anterior e posterior, respectivamente, séries essas separadas por uma área edêntula. Ligamento parcialmente externo, anfidético e resílio central implantado num resilífero inclinado iniciando sob os umbos e alongando-se em direção posterior. De cada lado do resilífero triangular ocorre uma área ligamentar reta, com algum resquício de ligamento preservado. Margem interna com três campos de crenulações denticulares, dois adjacentes respectivamente às séries anterior e posterior de dentes da charneira, e um terceiro na margem ventral.

[Operação] - Estações de coleta: [I] - 4381(12), 4412(04); [II] - "Ferraz"(01); [III] - 4743(04), 4756(01); [IV] - 4862(11), 4866(01), 4869(01), 4872 (63), 4874(01), 4875(671); [V] - 5036(10), 5051(02), 5052(02), "Livingston(C)" (46).

Distribuição: ao redor do continente antártico, Península Antártica até Shetland do Sul, Orcadas do Sul e Ilhas Sandwich do Sul até Geórgia do Sul, em profundidades de 18 a $1120 \mathrm{~m}$ (DELL 1990).

\section{Limidae Rafinesque, 1815 \\ Limatula Wood, 1839 \\ Limatula pygmaea (Philippi, 1845)}

Fig. 23

Lima pygmaea Philippi, 1845: 56.

Concha oval-oblonga no sentido da altura (maior exemplar $=11 \mathrm{~mm}$ de comprimento), branca, fina, equivalve. Umbos centrais, pouco proeminentes sobre a área ligamentar. Margem dorsal curta, com lados ligeiramente inclinados ventralmente, formando ângulo obtuso amplo; aurículas pequenas, igualmente desenvolvidas. Perióstraco ausente. Superfície ornamentada com 16 a 25 costelas de largura similar à dos sulcos intercostais, concentradas na área mediana das valvas; áreas 

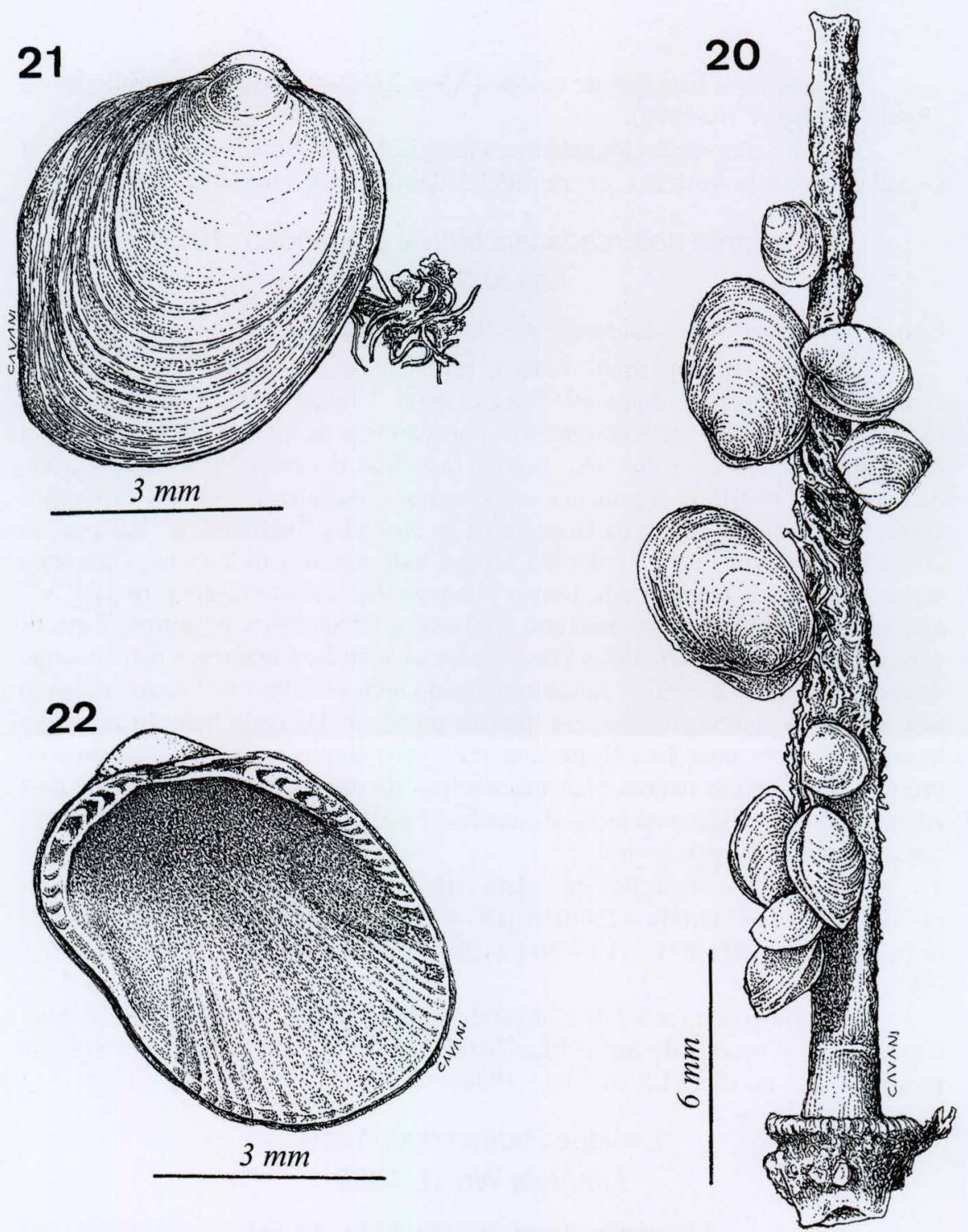

Figs 20-22. Lissarca notorcadensis: (20) espécimes fixos pelo bisso a um espinho de ouriço-do-mar, (21) concha vista pela valva direita, (22) vista interna da valva direita.

laterais anterior e posterior desprovidas de costelas, ou com raras costelas obsoletas. Costelas radiais e interespaços cruzados por estrias baixas, muito numerosas, próximas, que se prolongam por toda área lisa nas laterais e sobre as aurículas, onde constituem a única ornamentação presente. Até seis linhas de crescimento presentes. Charneira edêntula, estreita. Porção principal do ligamento fixo a um resilífero raso, triangular, sob o umbo; parte do ligamento estendendo-se da porção principal para 

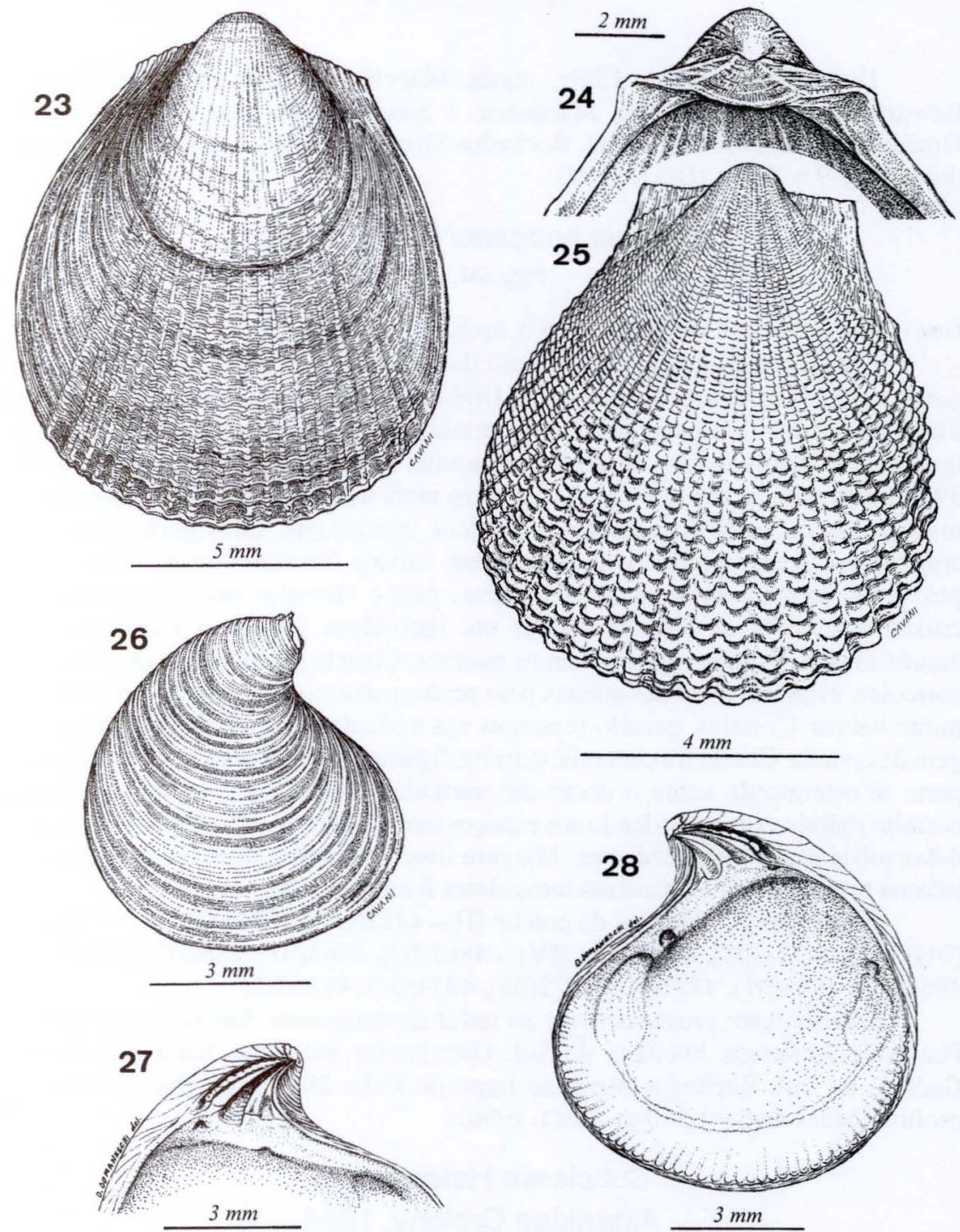

Figs 23-28. Concha vista pela valva direita: (23) Limatula pygmaea, (25) L. hodgsoni, (26) Astarte longirostris. Detalhe da charneira da valva esquerda: (24) L. hodgsoni, (27) $A$. longirostris. Vista interna da valva direita: (28) A. longirostris.

ambos os lados sobre o dorso das aurículas. Superfície interna da concha com duas a três costelas radiais evidentes, correspondendo a espaços intercostais na superfície externa, estendendo-se ao longo da linha mediana das valvas e se sobressaindo na margem ventral como uma forte crenulação denticular. Superfície restante lisa ou com raras costelas radiais fracas próximo à área marginal.

[Operação] - Estações de coleta: [IV] - 4866(c/v); [VI] - E(c/v). 
Distribuição: sul do Chile, região Magelânica, Ilhas Falkland, Príncipe Edward, Marion, Kerguelen, Macquarie e Sandwich do Sul, Geórgia do Sul, Orcadas do Sul, Shetland do Sul, Rochedos Shag, Península Antártica, em profundidades de 9 a 274 m (DELL 1990).

\section{Limatula hodgsoni (Smith, 1907)}

Figs 24,25

Lima (Limatula) hodgsoni Smith, 1907: 6, pl. 3, figs 8, 8a.

Concha oval-oblonga no sentido da altura (maior exemplar $=27 \mathrm{~mm}$ de comprimento), branca, fina, equivalve. Umbos centrais, pouco proeminentes sobre a área ligamentar. Margem dorsal curta, praticamente reta, com aurículas pequenas, igualmente desenvolvidas. Perióstraco ausente. Superfície ornamentada com 26 a 39 costelas radiais, sendo 30 a 36 o número mais freqüente. Costelas podendo ser mais largas ou mais estreitas que os sulcos intercostais, estes geralmente mais amplos nas áreas anterior e posterior das valvas; lamelas concêntricas, muito próximas, formam escamas arredondadas, pouco elevadas mas conspícuas nos cruzamentos com as costelas radiais em indivíduos jovens, e freqüentemente danificadas ou erodidas nos espécimes maiores. Costelas ausentes ou obsoletas nas aurículas, estas esculturadas apenas pelo prolongamento das lamelas concêntricas muito baixas. Costelas, quando presentes nas aurículas, raramente atingem a margem da concha. Charneira edêntula, estreita; ligamento triangular, pequeno, central, parte se estendendo sobre o dorso das aurículas. Interior da concha com fracas costelas radiais, correspondendo aos espaços intercostais na superfície externa, duas delas subcentrais, mais evidentes. Margem livre levemente crenulada, subdenticulada na região central. Cicatrizes musculares fracamente impressas.

[Operação] - Estações de coleta: [I] - 4412(c/v), 4381(01); [II] - "Ferraz" (01); [III] - 4743(04), 4756(c/v); [IV] - 4862(02), 4863(01), 4864(01), 4866(c/v), 4867(02), 4868(01), 4871(12), 4872(09), 4874(01), 4875(02).

Distribuição: provavelmente ao redor do continente Antártico, ao largo da Península Antártica, Shetland do Sul, Orcadas do Sul, Ilhas Sandwich do Sul, Geórgia do Sul, Rochedos Shag, ao largo do Cabo Horn e da Ilha Bouvet, em profundidades de 6 a $1.180 \mathrm{~m}$ (DELL 1990).

\section{Subclasse Heterodonta \\ Astartidae Orbigny, 1844 \\ Astarte Sowerby, 1816}

\section{Astarte longirostris Orbigny, 1846}

Figs 26, 27, 28

Astarte longirostra Orbigny, 1846: 576, pl. 83, figs 19-22.

Concha subpiriforme, pequena (maior exemplar $=8 \mathrm{~mm}$ de comprimento), comprimida, equivalve e inequilateral; altura e comprimento iguais ou altura maior, acentuando o aspecto piriforme. Umbos prosógiros, não raro, erodidos; região umbonal pouco a fortemente elevada. Margem dorsal anterior fortemente inclinada, 
arqueada, seguindo a concavidade acentuada das valvas na área lunular. Lúnula inconspícua. Escudo longo, estreito; margem dorsal posterior convexa, fortemente inclinada, confluindo com a margem posterior que é suavemente convexa a reta; margem anterior curta, uniformemente arredondada e margem ventral convexa, amplamente arredondada. Perióstraco espesso, marrom-oliváceo, frequientemente erodido nos umbos, ultrapassando e recobrindo parcialmente a margem livre das valvas; quando ressequido destaca-se da concha. Superfície externa das valvas com costelas concêntricas baixas, arredondadas, de largura próxima a dos interespaços, onde se destacam de uma a três estrias concêntricas fracas. Charneira estreita, alta; valva direita com um dente central forte, de seção transversal quadrangular, prolongando-se e se espessando a partir do umbo em direção ventral posterior; junto à margem anterior fraca elevação denticular. Uma placa calcária baixa, delgada, de igual extensão à do dente mediano, limita com a borda dorsal da valva o sulco de fixação do ligamento; valva esquerda com um dente anterior similar em desenvolvimento ao dente de posição central na valva oposta, e uma forte placa calcária, similar em desenvolvimento ao dente anterior, limita com a margem dorsal da valva o sulco ligamentar. Ligamento opistodético, estreito, alongado, saliente na região do escudo, e de igual extensão à do maior dente nas valvas. Interior da concha branco, liso, com a ornamentação da face externa vista através das valvas semitransparentes; margem livre interna das valvas com crenulação denticular em toda a extensão, ou lisa em alguns espécimes; cicatrizes dos adutores iguais, ovaladas, conspícuas em alguns espécimes. Linha palial pouco marcada; cicatriz do retrator anterior do pé isolada da do adutor, e aprofundada; cicatriz do retrator posterior rasa, contígua ou unida a do adutor posterior. Concavidade subumbonal ausente.

[Operação] - Estações de coleta: [IV] - 4875(01).

Distribuição: região Magelânica e Ilhas Falkland, Sul da Argentina, Geórgia do Sul, Ilhas Príncipe Edward, Marion e Kerghelem, em profundidades de 8 a 845 m (DELL 1990).

\section{Carditidae Fleming, 1828 Cyclocardia Conrad, 1867 \\ Cyclocardia astartoides (Martens, 1878)}

Fig. 29

Cardita astartoides Martens, 1878: 25.

Concha ovalada (maior exemplar $=36 \mathrm{~mm}$ de comprimento), sólida, equivalve e inequilateral. Umbos prosógiros, baixos. Margem dorsal anterior côncava e posterior convexa; margens anterior curta, arredondada, posterior mais alta, arredondada a truncada e margem ventral ampla, arqueada. Perióstraco espesso, com corrugações concêntricas e coloração variando de marrom-olivácea clara a quase negra. Ornamentação da concha constituída por 16 a 25 costelas radiais, regulares, que se tornam menos proeminentes e mais amplas em direção à margem ventral. Costelas radiais cruzadas por numerosas estrias concêntricas. Charneira com dentes cardinais conspícuos e dentes laterais obsoletos. Valva direita com três dentes, o cardinal anterior pequeno, estreito, prolongando-se a partir do umbo em direção ântero-ventral como uma 
elevação espessada da margem da concha; dente mediano robusto, distintamente bífido sob o umbo, alargando-se em direção ventral e alongando-se posteriormente; dente posterior estreito alongando-se em direção ventral e posterior. Valva esquerda com cardinal anterior curto, espesso, bífido, inclinado em direção anterior, e cardinal posterior robusto, ligeiramente bífido e alongando-se posteriormente. Ligamento espesso, alongado, quase inteiramente interno e fixo a cada valva em um sulco estreito e longo. Superfície interna da concha branca, com elevações radiais tênues, correspondendo aos espaços intercostais na face externa, terminando na margem livre como crenulações fortes que interdigitam com as da valva oposta. Cicatrizes dos adutores conspícuas, subiguais, a anterior mais estreitada e separada da cicatriz do retrator anterior do pé. Linha palial bem marcada; seio palial ausente.

[Operação] - Estações de coleta: [II] - "Ferraz"(c/v); [III] - 4743(01), 4756(c/v); [IV] - 4861(02), 4865(01), 4866(02), 4868(06), 4870(01), 4871(13), 4872(01), 4874(10), 4875(11); [V] - 5033(c/v), 5052(05).

Distribuição: ao redor do continente Antártico, Península Antártica, Shetland do Sul, Orcadas do Sul, Ilhas Sandwich, Geórgia do Sul, ao largo das Ilhas Bouvet e Kerguelen, em profundidades de 18 a 1674 m (DELL 1990).

\section{Cyamiidae Philippi, 1845 \\ Cyamiomactra Bernard, 1897}

\section{Cyamiomactra laminifera (Lamy, 1906)}

Figs $30,48,49$

Mactra (Heteromactra) laminifera Lamy, 1906a: 45, fig. 1.

Concha geralmente quadrangular arredondada, branca, equivalve, inequilateral, mais comprida que alta (maior exemplar $=7 \mathrm{~mm}$ de comprimento), com contorno variável. Carena de desenvolvimento variável, muito forte e conspícua em uns, fraca ou ausente em outros exemplares, estende-se dos umbos até a margem ventral posterior. Umbos ortógiros, subcentrais anteriores, baixos, arredondados e muito próximos. Prodissoconcha presente em muitos espécimes, hialina e ornamentada por punctuações microscópicas. Margem posterior da dissoconcha suavemente arredondada a obliquamente truncada, e neste caso com angulosidade correspondendo ao término da carena quando presente. Margem anterior ligeiramente mais curta que a posterior e uniformemente arredondada; margem ventral ligeiramente convexa ou quase reta em alguns espécimes. Concha revestida por perióstraco liso, fino, castanhooliváceo, com estrias concêntricas microscópicas, dando aspecto sedoso à superfície. Valva direita com dois dentes cardinais lamelares, divergindo e se espessando a partir do umbo. Região mais espessa de cada dente bífida e com aspecto de duas lâminas justapostas. Valva esquerda com dente cardinal mediano forte, triangular, bífido, lembrando um "V" invertido, e acompanhado nos lados anterior e posterior por um dente laminar espesso e bastante elevado. Ligamento interno, preso a um resilífero estreito que se alonga a partir do umbo em direção posterior. Interior da concha liso ou com sulcos concêntricos arredondados, correspondendo as paradas no crescimento. Margem interna lisa; cicatrizes dos adutores alongadas e seio palial ausente. 

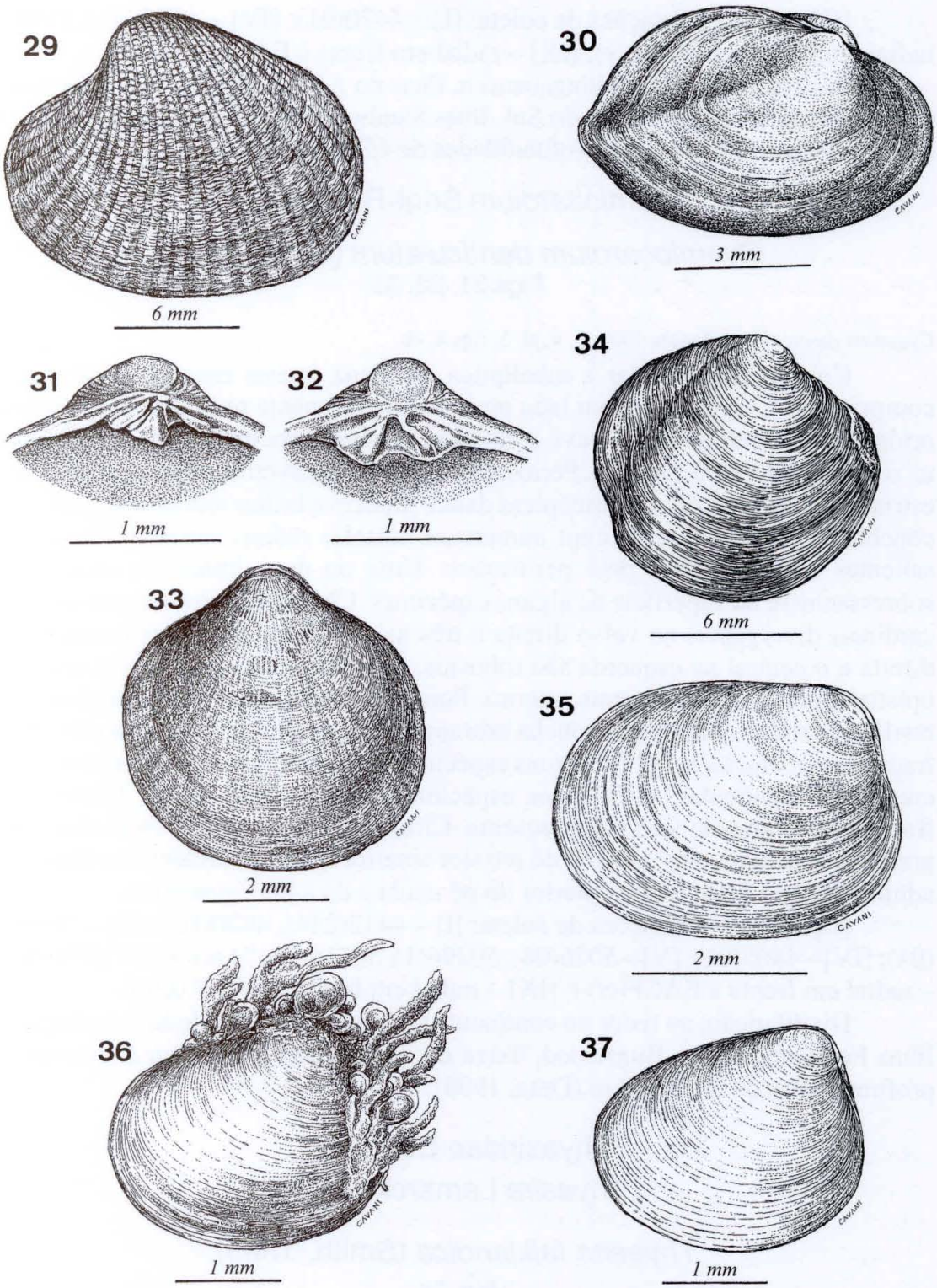

Figs 29-37. Concha vista pela valva esquerda: (29) Cyclocardia astartoides, (33) Cyamiocardium denticulatum, (35) Mysella miniuscula, (36) M. charcoti com o epibionte Monobrachium (Hydrozoa-Cnidaria), (37) M. charcoti. Concha vista pela valva direita: (30) Cyamiomactra laminifera, (34) Thyasira falklandica. Detalhe da charneira de C. denticulatum: (31) valva esquerda, (32) valva direita. 
[Operação] - Estações de coleta: [I] - 4420(01); [IV] - 4866(c/v); [VIII] radial em frente à $\operatorname{EACF}(\mathrm{c} / \mathrm{v}) ;[\mathrm{IX}]$ - radial em frente à $\operatorname{EACF}(2)$.

Distribuição: Mar Bellingshausen, ilhas do Arco Escócia, Península Antártica, Shetland do Sul, Orcadas do Sul, Ilhas Sandwich do Sul, Geórgia do Sul, e ao largo das Ilhas Falkland, em profundidades de 15 a 1.281 m (DELL 1990).

\section{Cyamiocardium Soot-Ryen, 1951 \\ Cyamiocardium denticulatum (Smith, 1907) \\ Figs 31, 32, 33}

Cyamium denticulatum Smith, 1907: 3, 4, pl. 3, figs 4, 4b.

Concha suborbicular a subelíptica, pequena (maior exemplar $=6 \mathrm{~mm}$ de comprimento), equivalve, com lado posterior ligeiramente mais alongado. Umbos ortógiros, subcentrais anteriores e contíguos. Prodissoconcha circular, lisa, brilhante, sobressaindo-se nos umbos. Perióstraco fino, cinza-esverdeado a amarelado, com estrias concêntricas submicroscópicas dando aspecto e brilho sedoso à superfície da concha. Superfície externa com numerosas costelas radiais estreitas, fracamente salientes e semi-ocultas pelo perióstraco. Uma ou duas linhas de crescimento sobressaem-se na superfície de alguns espécimes. Charneira forte, com dois dentes cardinais divergentes na valva direita e três na esquerda, dos quais o anterior na direita e o central na esquerda são robustos, salientes e quase bífidos. Ligamento opistodético, quase totalmente interno. Porção interna do ligamento alojada num resilífero estreito. Interior da concha esbranquiçado, praticamente liso a não ser por fraca ornamentação radial em alguns espécimes, terminando na margem livre como crenulação denticular, visível nos espécimes melhor preservados. Linha palial fracamente marcada; seio palial ausente. Cicatrizes dos adutores, oval-alongadas, grandes, bem marcadas; cicatriz do retrator anterior do pé geralmente isolada da do adutor; cicatriz do retrator posterior do pé unida a do adutor posterior.

[Operação] - Estações de coleta: [I] - 4412(214), 4420(80); [II] - "Ferraz" (01); [IV] - 4865(01); [V]-5026(08), 5029(01), 5031(c/v), "Arctowski"(03); [VIII] - radial em frente à EACF $(\mathrm{c} / \mathrm{v}) ;[\mathrm{IX}]$ - radial em frente à EACF $(\mathrm{c} / \mathrm{v})$.

Distribuição: ao redor do continente antártico, Shetland do Sul, ao largo das Ilhas Falkland, Banco Burdwood, Terra do Fogo, Ilhas Kerguelen e Bouvet, em profundidades de 5 a $1.180 \mathrm{~m}$ (DELL 1990).

\section{Thyasiridae Dall, 1901 \\ Thyasira Lamarck, 1818}

\section{Thyasira falklandica (Smith, 1885)}

Fig. 34

Cryptodon falklandicus Smith, 1885: 190, pl. 14, figs 3, 3a.

Concha subcircular (maior exemplar $=14 \mathrm{~mm}$ de comprimento), exceto na metade ventral da margem posterior que é quase reta, subequilateral, equivalve. Depressão suave, acompanhada de elevação arredondada, ambas típicas dos tiazirídeos, prolongam-se e se alargam a partir dos umbos até a confluência da margem 
ventral com a margem posterior. Incrustação geralmente espessa, firmemente aderida, constituída de finas partículas do sedimento é freqüente na margem e declive anterior da concha, por onde se dá a saída do pé. Umbos prosógiros, pequenos, contíguos. Perióstraco fino, amarelado ou castanho-esverdeado. Ornamentação constituída por poucas linhas de crescimento conspícuas, intercaladas por estriações concêntricas, ambas melhor preservadas na área coberta pelo perióstraco. Charneira edêntula, ligeiramente espessada na sua região posterior onde se situa o longo sulco que aloja o ligamento opistodético. Interior da concha esbranquiçado, com cicatrizes dos adutores bem marcadas, a do anterior mais desenvolvida e alongada que a do posterior. Seio palial ausente.

[Operação] - Estações de coleta: [II] - "Ferraz"(01); [V] - 5026(01), 5027(c/v); [VIII] - radial em frente à EACF(30); [IX] - radial em frente à EACF (06).

Distribuição: Espécie de distribuição primariamente subantártica, ocorrendo na região Magelânica, Ilhas Falklands, Geórgia do Sul, Orcadas do Sul, Rochedo Shag, e estendendo-se pela região antártica até a Península Palmer, em profundidades de 5 a 344 m (NICOL 1966).

\section{Lasaeidae Gray, 1842}

Mysella Angas, 1877

\section{Mysella miniuscula (Pfeffer, 1886)}

Figs $35,50,51$

Nucula miniuscula Pfeffer in Martens \& Pfeffer, 1886: 128, pl. 4, fig. 15.

Concha ovalada, esbranquiçada, pequena (maior exemplar $=3,5 \mathrm{~mm}$ de comprimento), translúcida, equivalve, fortemente inequilateral. Umbos ortógiros, subterminais; região umbonal moderadamente inflada. Lado anterior muito alongado, amplo; margem dorsal anterior com declive suave, praticamente retilínea e margem anterior alta, uniformemente arredondada. Lado posterior muito curto, com margem dorsal curta, inclinada ventralmente; margem posterior estreita, uniformemente arredondada na confluência com a margem ventral ampla e convexa. Perióstraco forte, aderido, translúcido, de coloração amarelada. Valvas ornamentadas por estrias concêntricas finas e numerosas, algumas mais proeminentes. Charneira estreita, curta; valva direita com dois dentes cardinais pequenos, subiguais em forma e tamanho, divergentes e separados por uma fosseta ligamentar abaixo do umbo. Charneira da valva esquerda apenas com depressões rasas, pouco conspícuas, anterior e posterior ao umbo, onde se apoiam os dentes cardinais da valva direita. Valva esquerda com margens anterior e posterior ao resilífero com espessamento denticular que se encaixa numa depressão rasa junto a base e face externa de cada um dos dentes cardinais da valva direita. Linha palial larga, bastante recuada da margem interna, lisa; seio palial ausente. Cicatrizes do músculo retrator posterior do pé e adutor posterior, unidas, de contorno ovalado, semelhantes na forma e tamanho às cicatrizes do músculo retrator anterior do pé e adutor anterior, também unidas.

[Operação] - Estações de coleta: [V] - 5026(01); [VIII] - radial em frente à $\mathrm{EACF}(01) ;[\mathrm{IX}]$ - radial em frente à $\mathrm{EACF}(01)$. 
Distribuição: Mar de Ross, Terra Adelie, Península Antártica, Geórgia do Sul, Orcadas do Sul, Ilhas Sandwich do Sul, Shetland do Sul, em profundidades de 6 a 351 m (DELL 1990).

\section{Mysella charcoti (Lamy, 1906)}

Figs $36,37,52,53$

Montaguia charcoti Lamy, 1906a: 46, fig. 2.

Concha de contorno triangular-ovalado a ovalado, esbranquiçada, pequena (maior exemplar $=3 \mathrm{~mm}$ de comprimento), equivalve e fortemente inequilateral. Umbos ortógiros, subterminais a terminais posteriores, muito próximos. Região umbonal inflada, projetando-se em direção dorsal e posterior. Essa característica da região umbonal e a convexidade da margem ventral acentuam o contorno triangularovalado da concha e tornam o comprimento e altura quase iguais em alguns espécimes. Lado anterior muito alongado, com margem dorsal praticamente retilínea e margem anterior uniformemente arredondada. Lado posterior muito curto, com margem dorsal fortemente íngreme e margem posterior curta, revelando tênue angulosidade na confluência com a margem ventral convexa. Perióstraco castanho claro a quase incolor, forte, aderido, translúcido; perióstraco com estrias concêntricas muito finas, regularmente espaçadas, próximas e evidentes sob microscópio de luz. Valvas ornamentadas por finas e numerosas estrias concêntricas, regularmente distribuídas e próximas. Charneira da valva direita com dois dentes cardinais fortes, divergindo a partir do umbo e subparalelos respectivamente às margens dorsais anterior e posterior. Cardinal anterior cerca de duas vezes mais longo que o posterior, ambos separados por uma fosseta ligamentar sob o umbo. Charneira da valva esquerda apenas com depressões rasas anterior e posterior ao umbo, pouco conspícuas, onde se apoiam os dentes cardinais da valva direita. Margens da valva esquerda, anterior e posterior ao resilífero, com espessamento denticular que se encaixa numa depressão rasa ao longo da base e face externa dos dentes cardinais da valva direita. Superfície interna com linha palial larga, bastante recuada da margem interna, lisa; seio palial ausente. Cicatrizes do músculo retrator posterior do pé e do adutor posterior unidas, de contorno ovalado e menos alongado que o da cicatriz conjunta do retrator anterior do pé e adutor anterior, também unidas. Incrustação espessa e rígida formada por finas partículas do sedimento é freqüente sobre a região umbonal e margem posterior. Essa incrustação mascara o contorno real dessas regiões e modifica o contorno geral da concha. A espécie freqüentemente está associada com Monobrachium, hidróides epibiontes comensais. A remoção dos epibiontes, bem como a da incrustação de partículas exige raspagens que afetam o perióstraco e a camada prismática da concha, dificultando a identificação desta pelas características externas.

[Operação] - Estações de coleta: [III] - "Ilha Snow"(01); [IV] - 4864(c/v); [VI] - D(108); [VIII] - radial em frente à $\operatorname{EACF}(1665)$; [IX] - radial em frente à $\operatorname{EACF}(2397)$.

Distribuição: Mar de Bellingshausen, Península Antártica, ao largo da Shetland do Sul, Orcadas do Sul e Geórgia do Sul, Ilhas Kerguelen e Macquaire, em profundidades de 5 a $113 \mathrm{~m}$ (DELL 1990). 


\section{Subclasse Anomalodesmata \\ Lyonsiidae Fischer, 1827 \\ Lyonsia Turton, 1822}

\section{Lyonsia arcaeformis Martens, 1885}

Fig. 38

\section{Lyonsia arcaeformis Martens, 1885: 94.}

Concha oval-romboidal (maior exemplar $=11 \mathrm{~mm}$ de comprimento), moderadamente inflada, fina, semi-translúcida, fortemente inequilateral. Valva esquerda sobrepõe-se à valva direita ao longo dos dois terços posteriores da margem ventral; valva direita sobrepõe-se à valva esquerda na região posterior aos umbos. Umbos prosógiros, no terço anterior, muito próximos. Região anterior ao umbo curta, com margem anterior fortemente arqueada, angulosa; região posterior comprimida distalmente, com margem distal truncada e margem dorsal quase reta. Margem ventral amplamente curvada, convexa. Perióstraco castanho, fracamente aderido, melhor preservado na periferia e terço posterior da concha, freqüentemente incrustado com grãos minerais, espículas e microrganismos diversos. Superfície ornamentada por finas estrias de crescimento irregulares, intercruzadas por 20 a 30 estrias radiais finamente nodulosas, que aumentam em número por intercalação de novas estrias em direção à margem ventral. Interespaços das estrias radiais com densa nodulosidade submicroscópica, em nítido arranjo radial. Charneira edêntula; ligamento interno, alongado, opistodético. Superfície interna com margens lisas e cicatrizes musculares inconspícuas.

[Operação] - Estações de coleta: [IV] - 4871(2).

Distribuição: provável distribuição circum-antártica, com registro desde os $53^{\circ} \mathrm{E}$ até o Mar de Ross, Península Antártica, Shetland do Sul, Orcadas do Sul, Geórgia do Sul, em profundidades de 12 a 1.771 m (DELL 1990).

\section{Thraciidae Stoliczka, 1870 \\ Thracia Blainville, 1824 \\ Thracia meridionalis Smith, 1885}

Fig. 39

Thracia meridionalis Smith, 1885: 68, pl. 6, figs 4, 4 b.

Concha geralmente oblonga (maior exemplar $=37 \mathrm{~mm}$ de comprimento), subquadrada, mas de forma variável, fracamente inequivalve. Valva direita mais convexa, sobrepondo-se à valva esquerda por toda a extensão da margem ventral e margem anterior até as proximidades dos umbos. Umbos ortógiros, pequenos, subcentrais e muito próximos. Região umbonal direita mais elevada que a esquerda. Declive posterior em alguns espécimes com uma elevação fraca, arredondada, estendendo-se dos umbos até a confluência da margem ventral com a margem posterior. Margem dorsal posterior praticamente reta, e margem anterior fracamente convexa, ambas inclinadas em direção ventral. Margem anterior curta, uniformemente arredondada; margem posterior alta, subtruncada a truncada; margem ventral 

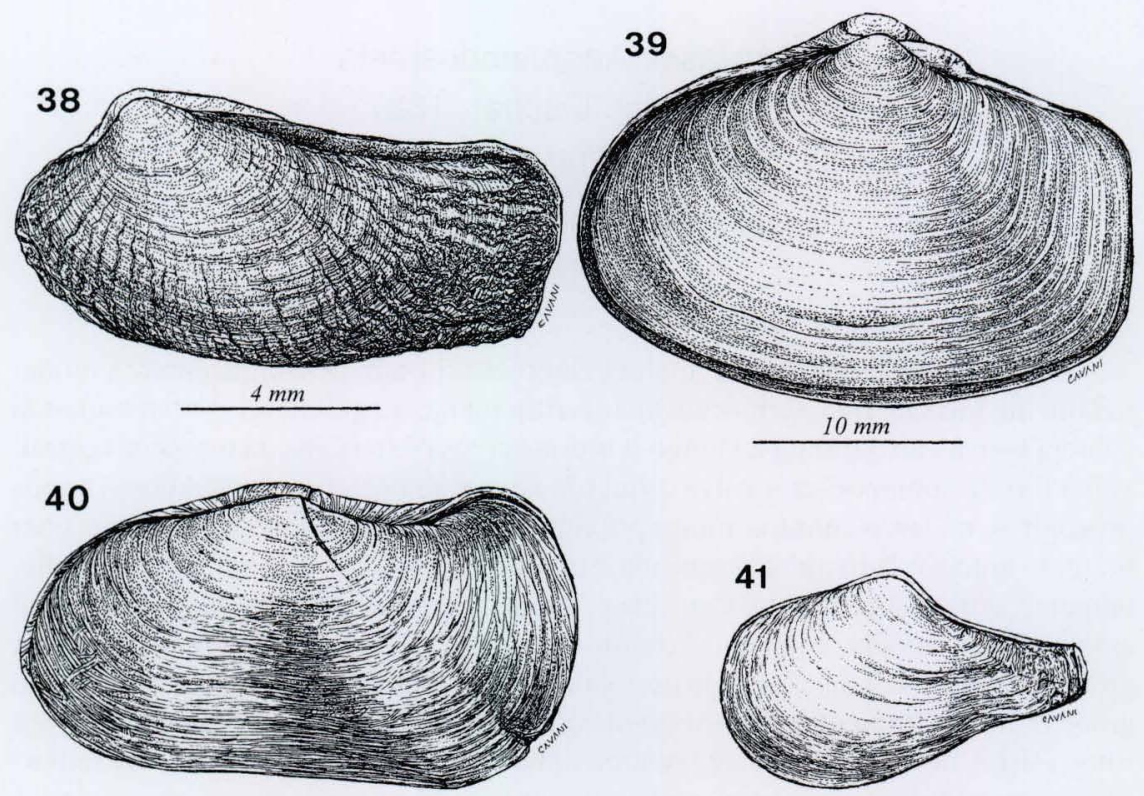

$20 \mathrm{~mm}$

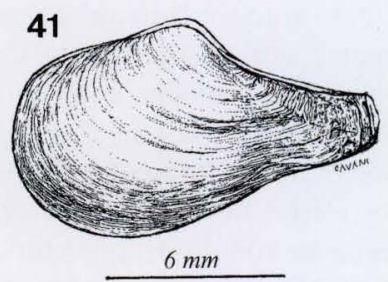

Figs 38-41. Concha vista pela valva esquerda: (38) Lyonsia arcaeformis, (39) Thracia meridionalis, (40) Laternula elliptica, (41) Cuspidaria infelix.

reta a ligeiramente convexa, com a valva direita sobrepondo-se à esquerda. Perióstraco oliváceo a marrom-claro, fino, aderido, freqüentemente incrustado com finas partículas do sedimento. Ornamentação constituída por numerosíssimas estrias concêntricas, algumas delas mais destacadas, marcando paradas no crescimento. Elevações concêntricas e algumas radiais, fracas, arredondadas, presentes em alguns espécimes, correspondem a deformidades durante o crescimento. Exceto para espécimes muito pequenos e para as partes desgastadas da concha dos adultos, a superfície externa apresenta uma granulosidade microscópica, fracamente organizada em fileiras concêntricas e defasadas em relação às estrias de mesma posição. Charneira edêntula. Valvas com uma plataforma interna espessada, posterior aos umbos, servindo de ponto de fixação para o ligamento opistodético, externo, curto, elevado. Interior da concha esbranquiçado, brilhante, com ondulações concêntricas, correspondendo às ondulações na face externa. Linha palial com seio palial amplo, ligeiramente inclinado em direção dorsal. Cicatriz do músculo adutor anterior mais estreita, menor e mais alongada que a do posterior.

[Operação] - Estações de coleta: [II] - "Ferraz"(c/v); [IV] - 4864(02), 4868(c/v), 4869(01); [V] - 5026(01), 5041(01), 5052(01).

Distribuição: provavelmente circum-antártica, estendendo-se pela Península Antártica, Shetland do Sul, Orcadas do Sul, Ilhas Sandwich do Sul, Geórgia do Sul até a região Magelânica, Ilhas Falkland, Kerguelen, Marion e Príncipe Edward, em profundidades de 5 a $752 \mathrm{~m}$ (DELL 1990). 


\section{Laternulidae Hedley, 1918 \\ Laternula Röding, 1798 \\ Laternula elliptica (King \& Broderip, 1831)}

Fig. 40

Anatina elliptica King \& Broderip, 1831: 335.

Concha oblonga, de coloração esbranquiçada, grande (maior exemplar $=93$ mm de comprimento), subequilateral; valva esquerda ligeiramente mais convexa que a direita, ambas deixando abertura posterior grande e abertura anterior comparativamente pequena. Umbos opistógiros, submedianos posterior, pequenos e contíguos. Umbos com uma fissura no lado posterior, prolongando-se ventralmente por $1 / 3$ a $1 / 2$ da altura das valvas; fissura visível como uma linha escura e conspícua no interior e/ou exterior das valvas. Margem dorsal anterior suavemente convexa, confluindo com a margem anterior curta e fortemente arcuada. Margem dorsal posterior côncava, elevando-se distalmente antes da confluência com a margem posterior alta, convexa a truncada; margem ventral quase reta. Perióstraco fino, de aspecto enrugado, acompanhando as estrias irregulares na superfície da concha; perióstraco de coloração cinza ou castanha, freqüentemente mascarada pela aderência de partículas finas do sedimento. Linhas de crescimento geralmente presentes. Ambas as valvas com duas elevações fracas, arredondadas, que se prolongam radialmente para a margem ventral, a partir dos umbos; elevação posterior mais proeminente que a anterior e se alargando em direção à confluência da margem ventral com a margem posterior. Cada elevação é acompanhada no interior das valvas por uma depressão correspondente. Superfície externa ornamentada por costelas concêntricas finas, descontínuas, e por numerosíssimas estrias microscópicas irregularmente inclinadas. Charneira edêntula. Ligamento interno preso a um condróforo pequeno, em forma de concha e se projetando sob os umbos. Condróforo suportado por uma elevação calcária laminar, que se prolonga em direção ventral e posterior, paralela à fissura originada nos umbos. Interior da concha brilhante iridescente, com numerosas ondulações concêntricas; margem interna lisa. Linha palial com seio palial raso, amplo. Cicatriz dos adutores pequenas, alongadas, próximas à margem dorsal.

[Operação] -Estações de coleta: [V] - 5026(03); [VI] -D(09); [VIII] - radial em frente à $\mathrm{EACF}(04) ;[\mathrm{IX}]$ - radial em frente à $\operatorname{EACF}(01)$.

Distribuição: completamente circum-antártica, Península Antártica, Shetland do Sul, Orcadas do Sul, Ilhas Sandwich do Sul, Geórgia do Sul e Kerguelen, em profundidades de 1 a 508 m (DELL 1990).

Cuspidariidae Dall, 1886

Cuspidaria Nardo, 1840

\section{Cuspidaria infelix Thiele, 1912}

Fig. 41

Cuspidaria infelix Thiele, 1912: 233, pl. 18, fig. 28.

Concha rostrada, branca, pequena (maior exemplar $=13 \mathrm{~mm}$ de comprimento),

Revta bras. Zool. 19 (3): $645-675,2002$ 


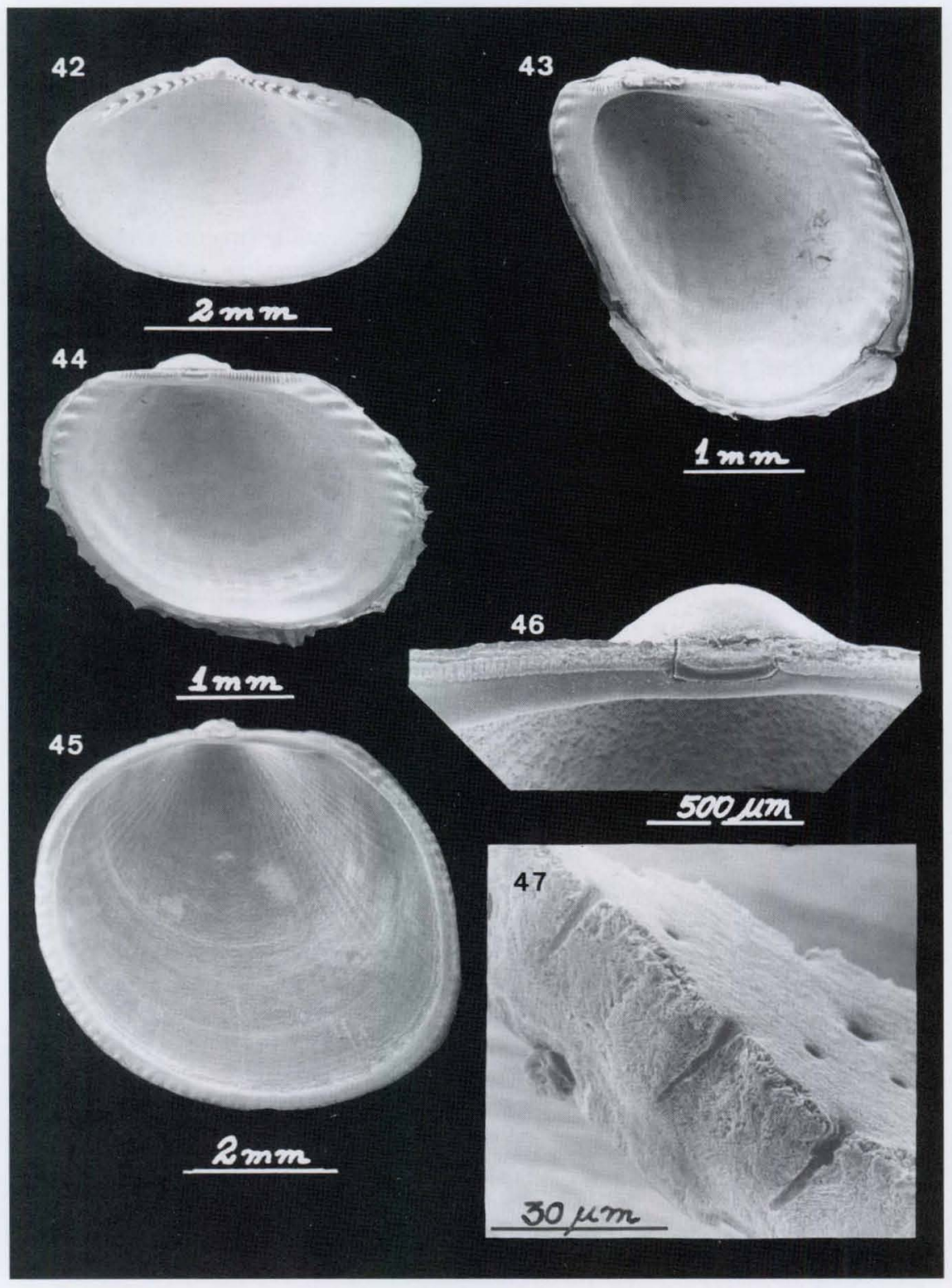

Figs 42-47. Vista interna da valva esquerda: (42) Nuculana inaequisculpta, (43) Philobrya wandelensis, (44) Adacnarca limopsoides, (45) A. nitens. Detalhe da charneira (46) de $A$. nitens, e de uma seção (47) da valva direita da mesma espécie, onde se evidenciam microtúbulos e respectivas aberturas. 


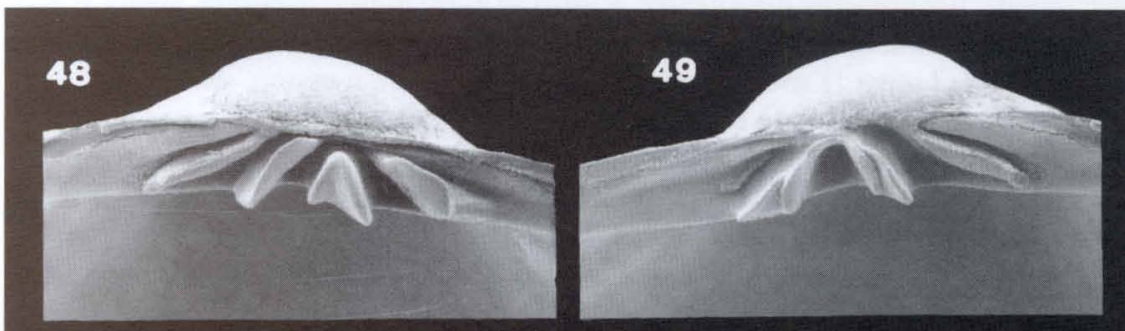

\section{$500 \mu m$}

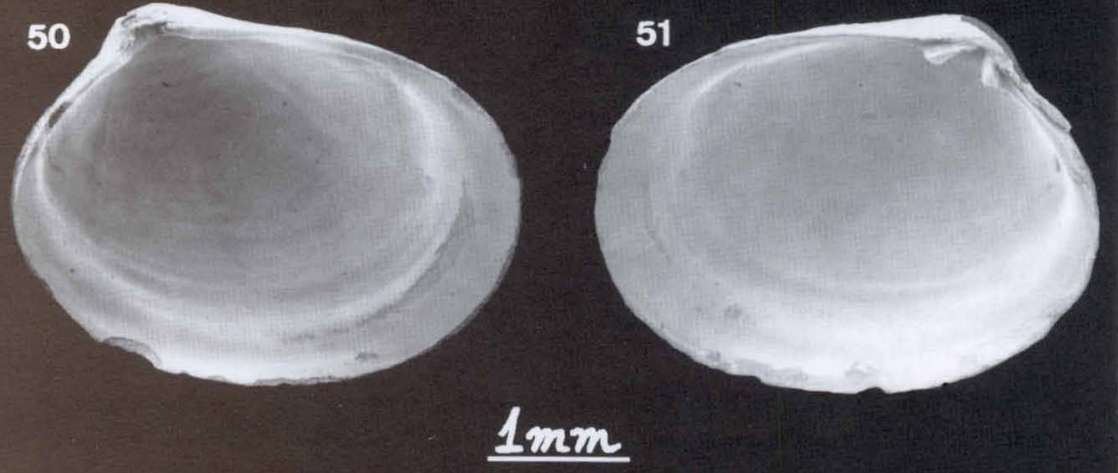
52
53

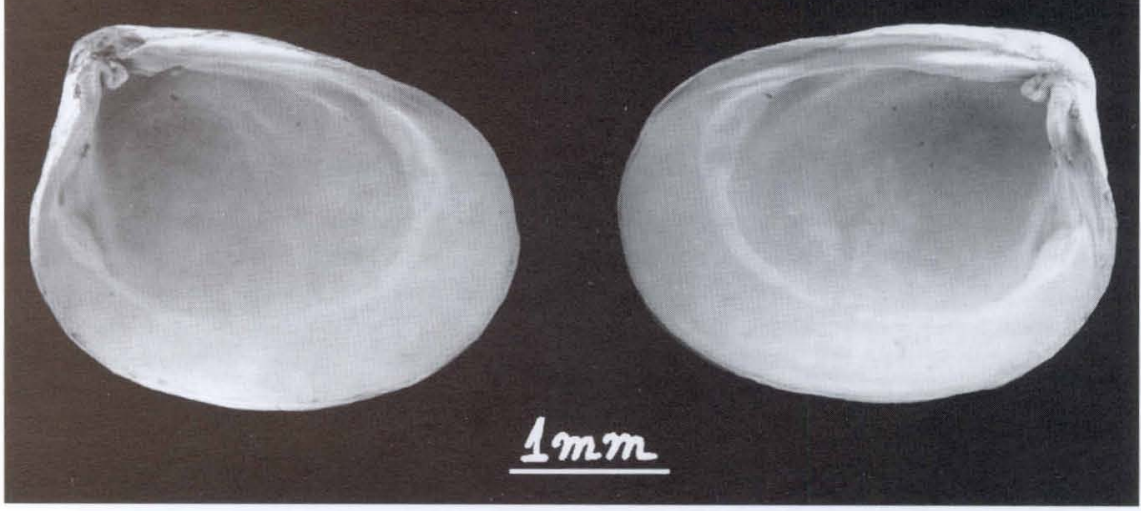

Figs 48-53. Detalhe da charneira da valva esquerda (48) e direita (49) de Cyamiomactra laminifera. Concha vista pela face interna: (50-51) valvas esquerda e direita, respectivamente, de Mysella miniuscula, (52-53) valvas esquerda e direita, respectivamente, de $M$. charcoti. 
fina, inflada, ligeiramente inequivalve. Rostro de extremidade truncada, aberta, e eixo longitudinal mediano situado dorsal e próximo ao eixo mediano longitudinal da concha. Valva esquerda sobrepondo-se à valva direita na margem ventral do rostro, valva direita sobrepondo-se à esquerda na margem dorsal do rostro. Umbos ortógiros, contíguos, subcentrais anteriores. Margem dorsal anterior fracamente convexa e dorsal posterior suavemente côncava próximo aos umbos a quase reta na região rostral; margens anterior e ventral uniformemente arredondadas, a ventral tornando-se fracamente sinuosa na base do rostro e se elevando dorsalmente até a extremidade deste último. Perióstraco castanho claro, presente na margem ventral e particularmente no rostro, onde é conspícuo, lamelar enrugado coincidente com as estriações concêntricas da concha. Ornamentação constituída por numerosas estrias finas, concêntricas, e algumas faixas com bordas fracamente elevadas simulando pregas. Charneira edêntula, com ligamento fixo a um condróforo igualmente desenvolvido nas valvas, projetando-se imediatamente posterior aos umbos e se alongando em direção posterior. Face interna das valvas e respectivas margens, lisas; superfície geral com fraca estriação concêntrica; cicatrizes musculares inconspícuas. 4874(01).

[Operação] - Estações de coleta: [IV] - 4863(c/v), 4864(01), 4872(c/v),

Distribuição: provavelmente ao redor do continente antártico, Península Antártica, Shetland do Sul, Orcadas do Sul, Geórgia do Sul e Ilha Bouvet, em profundidades de 91 a $752 \mathrm{~m}$ (DELL 1990).

AGRADECIMENTOS. Ao CNPq [Proc.: 300660/92-8 (RN); Proc.: 300490/94-1 (RE)]; ao $\mathrm{CNPq} / \mathrm{PROANTAR}, \mathrm{CIRM}$ e FAB, pelo auxílio financeiro e/ou apoio logístico às Operações Antárticas referidas no texto. À FAPESP pelo apoio ao projeto do terceiro autor (Proc. 99/02399-9), e à CAPES/PROAP por financiar as ilustrações. Ao Dr. A.A.G.F.C. Ribeiro, responsável pelo Laboratório de Microscopia Eletrônica do IB-USP e Sr. Ênio Mattos pelo suporte técnico com a MEV. À Dra. S.G.B.C. Lopes e Biól. C.E. Brancato pela colaboração na triagem inicial das amostras.

\section{REFERÊNCIAS BIBLIOGRÁFICAS}

ARNAUD, P.M. 1973. Invertebrés marins des XIIème et XVème Expéditions Antarctiques Françaises en Terre Adélie. 13. Polyplacophores, Scaphopodes et Pélécypodes. Téthys, Marseille, 5 (4): 549-560.

ARnAUd, P.M. 1974. Contribuition à la bionomie marine benthique des régions antarctiques et subantarctiques. Téthys, Marseille, 6 (3): 465-653.

COAN, E.V.; P.V. SCOTT \& F.R. BERNARD. 2000. Bivalve seashells of Western North America. Marine bivalve mollusks from Arctic Alaska to Baja California. Santa Barbara, Santa Barbara Museum of Natural History, VIII+764p.

DeLL, R.K. 1964. Antarctic and Subantarctic Mollusca: Amphineura, Scaphopoda and Bivalvia. Discov. Rep., Cambridge, 33: 93-250.

1972. Antarctic benthos. Adv. Mar. Biol., London, 10: 1-216.

1990. Antarctic Mollusca with special reference to the fauna of the Ross Sea. Bull. R. Soc.

N. Zealand 27: 1-311.

JAY, J.C. 1839. A catalogue of the recent shells arranged according to the Lamarckian system, together with descriptions of new or rare species contained in the collection of John C. Jay. New York, Wiley \& Putnam, $3^{\text {rd }}$ ed., 126p.

Revta bras. Zool. 19 (3): $645-675,2002$ 
King, P.P. \& W.J. BroderiP. 1831. Description of the Cirrhipeda, Conchifera and Mollusca, in a collection formed by the Officers of H. M. S. Adventure and Beagle employed between the years 1826 and 1830 in surveying the Southern Coasts of South America, including the Straits of Magalhaens and the Coast of Tierra del Fuego. Zool. Jour. 5: 332-349.

LAMY, E. 1906a. Lamellibranches recueillis par l'Expédition Antarctique Française du Dr Charcot. Bull. Mus. Hist. Nat. Paris 12: 44-52.

1906b. Sur quelques Mollusques des Orcades du Sud. Bull. Mus. Hist. Nat. Paris 12: 121-126.

-1910. Mission dans l'Antartique dirigé par M. le Dr Charcot (1908-1910): collections recueillis par M. le Dr. J. Liouville: Pélécypodes. Bull. Mus. Hist. Nat. Paris 16: 388-394.

MARTENS, E. 1878. Einige Conchylien aus den kalteren Meeresgegenden der südlichen Eidhalfte. S.B. Ges. naturf. Fr. Berlin 1878: 20-26.

1885. Vorläufige Mitteilungen über die Mollusken-Fauna von Süd Georgien. S. B. Ges. naturf. Fr. Berlin 1885: 89-94.

Martens, E. \& G. Pfeffer. 1886. Die Mollusken von Süd-Georgien nach den Ausbeute der Deutschen Station. Jahrb. Harburgischen Wiss. Anstalten 3: 65-135.

Melvill, J.C. \& R. Standen. 1907. The marine Mollusca of the Scottish National Antarctic Expedition. Trans. roy. Soc. Edinb. 46 (I) (5): 119-157.

NicoL, D. 1966. Descriptions, ecology and geographic distribution of some Antarctic pelecypods. Bull. Amer. Paleont. 51 (231): 1-102.

1967. Some characteristics of cold-water marine pelecypods. J. Paleont. 41 (6): 1330-1340. 1970. Antarctic pelecypod faunal peculiarities. Science 168 (3936): 1248-1249.

Nonato, E.F.; M.A.V. PetTi; P.C. Paiva \& T.A.S. Brito. 1992a. Programa Antártico Brasileiro: amostragem de organismos bentônicos realizadas nas seis primeiras expedições (1982 a 1988), com a participação do N/Oc. "Prof. W. Besnard". Relat. Int. Inst. oceanogr. Univ. São Paulo 32: 1-12.

Nonato, E.F.; T.A.S. Brito; P.C. Paiva \& M.A.V. PetTi. 1992b. Programa Antártico Brasileiro: projeto

"Bionomia da fauna bentônica Antártica". Atividades subaquáticas realizadas na Baía do Almirantado a partir da VI Expedição (1988). Relat. Int. Inst. Oceanogr. Univ. São Paulo 33: $1-12$.

Orbigny, A. 1835-1846. Mollusques. Voyage dans l'Amérique Méridionale. Voyage éxécuté pendant les annés $1826,1827,1828,1829,1830,1831,1832$ et 1833. Paris, 758p.

Pelseneer, P. 1903. Mollusques (amphineures, gastropodes et lamellibranches). Res. Voy. S.Y. Belgica Zool.: 1-85.

PHILIPPI, A. 1845. Diagnosen einiger neuen Conchylien. Arch. Naturgesch. 11: 50-71.

Powell, A.W.B. 1960. Antarctic and Subantarctic Mollusca. Rec. Auckl. Inst. Mus. 5 (3/4): 117-193. 1965. Mollusca of Antarctic and Subantarctic seas. Monogr. Biol., Dordrecht, 15: 333-380.

SMITH, E.A. 1885. Report on the Lamellibranchiata collected by H. M. S. "Challenger" during the years 1873-1876. Rep. Sci. Res. Voyage H.M.S. Challenger, Zool. 13: 1-341.

. 1907. Lamellibranchiata. Nat. Ant. Exped. ("Discovery") Nat. Hist. 2, Zool., Mollusca, 5: $1-7$.

1915. Mollusca. Part I. Gastropoda, Prosobranchia, Scaphopoda, and Pelecypoda. Brit. Antarct. ("Terra Nova”) Exped. 1910 Zool. 2 (4): 61-112.

Soot-Ryen, T. 1951. Antarctic pelecypodes. Scient. Results Norw. Antarct. Exped. 1927-1928 32: $1-46$.

THIELE, J. 1912. Die Antarktischen Schnecken und Muscheln. Dtsch. Südpolar-Exped. 1901-1903, 13, Zool. 5: 183-285.

Villarroel, M. \& J. Stuardo. 1998. Protobranchia (Mollusca: Bivalvia) chilenos recientes y algunos fósiles. Malacologia 40 (1-2): 113-229.

Recebido em 09.I.2002; aceito em 15.VII.2002. 